\title{
NDVI Indicates Long-Term Dynamics of Vegetation and Its Driving Forces from Climatic and Anthropogenic Factors in Mongolian Plateau
}

\author{
Enliang Guo ${ }^{1,2,3} \mathbb{D}$, Yongfang Wang ${ }^{1,2, * \mathbb{D}}$, Cailin Wang ${ }^{4}$, Zhongyi Sun ${ }^{5}$, Yulong Bao ${ }^{1,2}$, Naren Mandula ${ }^{1,2}$, \\ Buren Jirigala ${ }^{2,4}$, Yuhai Bao ${ }^{1}$ and $\mathrm{He} \mathrm{Li}^{6}$ (D)
}

check for

updates

Citation: Guo, E.; Wang, Y.; Wang, C.; Sun, Z.; Bao, Y.; Mandula, N.; Jirigala, B.; Bao, Y.; Li, H. NDVI Indicates Long-Term Dynamics of Vegetation and Its Driving Forces from Climatic and Anthropogenic Factors in Mongolian Plateau. Remote Sens. 2021, 13, 688. https://doi.org/ $10.3390 /$ rs13040688

Academic Editor: Eben North Broadbent

Received: 23 December 2020

Accepted: 10 February 2021

Published: 13 February 2021

Publisher's Note: MDPI stays neutral with regard to jurisdictional claims in published maps and institutional affiliations.

Copyright: (c) 2021 by the authors. Licensee MDPI, Basel, Switzerland. This article is an open access article distributed under the terms and conditions of the Creative Commons Attribution (CC BY) license (https:/ / creativecommons.org/licenses/by/ $4.0 /)$.
1 College of Geographical Science, Inner Mongolia Normal University, Hohhot 010022, China; guoel1988@imnu.edu.cn (E.G.); baoyulong@imnu.edu.cn (Y.B.); narenmandula@imnu.edu.cn (N.M.); baoyuhai@imnu.edu.cn (Y.B.)

2 Inner Mongolia Key Laboratory of Disaster and Ecological Security on the Mongolian Plateau, Inner Mongolia Normal University, Hohhot 010022, China; brjrgl@imnu.edu.cn

3 Lanzhou Institute of Arid Meteorology, China Meteorological Administration, Lanzhou 730020, China

4 Laboratory of National Land Space Planning and Disaster Emergency Management of Inner Mongolia, Chifeng University, Chifeng 024000, China; wangcailin@mail.bnu.edu.cn

5 College of Ecology and Environment, Hainan University, Haikou 570228, China; sunzy025@env.agr.hokudai.ac.jp

6 State Key Laboratory of Resources and Environmental Information System, Institute of Geographic Science and Natural Resources Research, Chinese Academy of Sciences, Beijing 100101, China; lih@lreis.ac.cn

* Correspondence: wangyongfang@imnu.edu.cn; Tel.: +86-155-6090-1656

Abstract: In recent years, global warming and intense human activity have been responsible for significantly altering vegetation dynamics on the Mongolian Plateau. Understanding the long-term vegetation dynamics in this region is important to assess the impact of these changes on the local ecosystem. Long-term (1982-2015), satellite-derived normalized difference vegetation index (NDVI) datasets were used to analyse the spatio-temporal patterns of vegetation activities using linear regression and the breaks for additive season and trend methods. The links between these patterns and changes in temperature, precipitation (PRE), soil moisture (SM), and anthropogenic activity were determined using partial correlation analysis, the residual trends method, and a stepwise multiple regression model. The most significant results indicated that air temperature and potential evapotranspiration increased significantly, while the SM and PRE had markedly decreased over the past 34 years. The NDVI dataset included $71.16 \%$ of pixels showing an increase in temperature and evaporation during the growing season, particularly in eastern Mongolia and the southern border of the Inner Mongolia Autonomous region, China. The proportion indicating the breakpoint of vegetation dynamics was $71.34 \%$ of pixels, and the trend breakpoints mainly occurred in 1993, 2003, and 2010. The cumulative effects of PRE and SM in the middle period, coupled with the short-term effects of temperature and potential evapotranspiration, have had positive effects on vegetation greening. Anthropogenic factors appear to have positively impacted vegetation dynamics, as shown in $81.21 \%$ of pixels. We consider rapid economic growth, PRE, and SM to be the main driving factors in Inner Mongolia. PRE was the main climatic factor, and combined human and livestock populations were the primary anthropogenic factors influencing vegetation dynamics in Mongolia. This study is important in promoting the continued use of green projects to address environmental change in the Mongolian Plateau.

Keywords: NDVI; climatic factors; anthropogenic factors; BFAST; Mongolian Plateau

\section{Introduction}

Vegetation is an important component of terrestrial ecosystems; it is a natural link between the soil and atmosphere, and an indicator of regional and global ecosystem 
stability [1]. Among existing vegetation indices, the normalized difference vegetation index (NDVI) is relatively easy to obtain and use in calculations, and also reflects surface vegetation conditions to a certain extent [2]. NDVI is a measure of the photosynthesising biomass amount and the state of plant health, as per the gross primary productivity of vegetation and leaf area index. It is able to detect the response of vegetation dynamics to climate change under multiple spatio-temporal scales [3-5]. The global inventory modelling and mapping studies (GIMMS) NDVI has been demonstrated to have the highest temporal consistency, including in trend analyses. Based on the latest generation of GIMMS NDVI (NDVI3g V1.0), long-term (>30 years) seasonal or annual trends in vegetation have been reported at the continental and global scales [6-8], including piecewise linear regression [9], polynomial fitting [10], and ensemble empirical mode decomposition (EEMD) method [11]. Furthermore, the time series with high frequency may describe the entire process of vegetation change over shorter time intervals. The breaks for additive seasonal and trend (BFAST) method has been widely used to detect seasonal, gradual, and abrupt changes in monthly NDVI time series. The breaks detected in the seasonal component represent a land cover change; as such, BFAST has been applied in many different regions to describe abrupt changes to land cover as a result of climate change or anthropogenic activity [12-14].

The impact of climate on vegetation dynamics is inevitable, and climate changeinduced changes in vegetation cover have had a direct impact on the material and energy balance of regional land-air interaction processes. For this reason, the role of climate on vegetation, which has had varying degrees of impact on vegetation globally, has received widespread attention from researchers [15-17]. However, using only linear relationships for very complex (and non-linear) processes is too simple for serious study. To clarify any correlation (including non-linear relationships) between impact factors, a geographical detector model has been developed to explore potential factors or explanatory variables from a spatial perspective [18], and accurately discern the compounding effect of various possible influences on vegetation change. In addition to climate, anthropogenic activity strongly affects the structure and function of terrestrial ecosystems, vegetation responses are a product of these effects. In areas experiencing intense anthropogenic activity, vegetation changes are often influenced by climatic and anthropogenic factors. Thus, various methods have been developed to distinguish human-induced vegetation dynamics from climate change-induced dynamics. Among them, the residual trend (RESTREND) method is considered a desirable and reasonable approach at large spatial scales [19], isolating and quantifying the contributions of different climatic and anthropogenic factors.

The Mongolian Plateau, a major component of the global grassland ecosystem, plays a pivotal role in East Asia and the global carbon cycle [20]. However, the region is located in arid and semi-arid climate areas, and its grassland ecosystems are particularly vulnerable to climate change. In recent decades, climate change in combination with frequent human activity, has caused increasing land degradation and desert expansion in the Mongolian Plateau [21]. Therefore, investigations into the long-term vegetation dynamics and its driving forces have become urgent issues in the region. The Mongolian Plateau is mainly composed of Mongolia and the Inner Mongolia (IMG) Autonomous Region, China. Due to China's Belt and Road Initiative (also known as One Belt, One Road), an increasing number of studies have been conducted within the Mongolian Plateau. This includes various statistical methods to distinguish vegetation change and responses to climate change or anthropogenic activity [22-25]. However, the BFAST algorithm was not adopted to analyse vegetation dynamics in the Mongolian Plateau. Previous studies have found that when it is used to analyse the response of vegetation to climate change, the cumulative impact is often masked due to variations and delays in responses from different types of vegetation cover. Additionally, under a long-term time scale, the NDVI and meteorological data are often analysed using averages, which also results in the partial loss of information. Previous studies have typically focused on the effects of temperature and precipitation on vegetation [26], ignoring the role of other climatic variables such as soil moisture, which can directly constrain plant photosynthesis [27]. The compounding effects of climatic and 
anthropogenic factors on vegetation dynamics is also an issue that has rarely been discussed in the literature.

This study was conducted to address the urgent need to analyse spatio-temporal variations in vegetation activity in different vegetation areas, and understand the vegetation responses to climatic and anthropogenic factors in the Mongolian Plateau. This research was carried out using a five-step process. First, we investigated changes in the climatic dynamics for different vegetation types and the pixel scale. Second, we investigated the long-term (1982-2015) interannual variations in NDVI at the pixel scale using the data-driven time series analysis method. The BFAST method was adopted to detect the breakpoints (BPs) of the NDVI in different vegetation areas at the pixel scale. Third, we applied statistical methods (i.e., partial correlation and time accumulated analysis) to screen out relationships between the NDVI and climatic factors at the pixel scale in the Mongolian Plateau. A geographical detector method was used to conduct the quantitative attribution analysis of climatic factors for NDVI from the single and compound affect perspective. Fourth, we implemented an approach based on the residual trends (RESTREND) method, enabling the quantification of anthropogenic factors. Finally, we estimated the effects of climatic and anthropogenic factors on NDVI variations using a stepwise multiple regression model. The findings of this study may serve as a knowledge base for projecting future vegetation growth trends, environmental changes, and understanding the ecosystem evolution of the Mongolian Plateau. Such a knowledge base is considered necessary to comprehensively assess the ecological security of the area.

\section{Materials and Methods}

\subsection{Study Area}

The Mongolian Plateau is located within the inner Asian plateau, and includes the entire territory of Mongolia, the IMG Autonomous Region, Gansu, Ningxia, and parts of the Shaanxi Province in China. Our literature review demonstrates that a majority of researchers have conducted research largely within the narrow Mongolian Plateau boundary, which includes the entire territory of Mongolia and the IMG region. According to the Köppen-Geiger climate classification [28], the Mongolian Plateau is located in arid, semiarid and subhumid regions, experiencing a typical continental climate (see Figure 1). The annual internal precipitation is mainly concentrated between May and October, the mean annual precipitation is from 50 to $400 \mathrm{~mm}$, and the maximum annual precipitation can reach $806.3 \mathrm{~mm}$ [29]. However, the precipitation in the Mongolian Plateau is much lower than the potential evapotranspiration (PET), producing a dry climate in this area [30]. Data on vegetation types were obtained from the National Atlas of Mongolia, and a 1:1,000,000 scale vegetation map of IMG was rasterised at $0.083^{\circ}$ [31]. Figure 1 illustrates the study location, and the different vegetation and steppe types map for the Mongolian Plateau. 


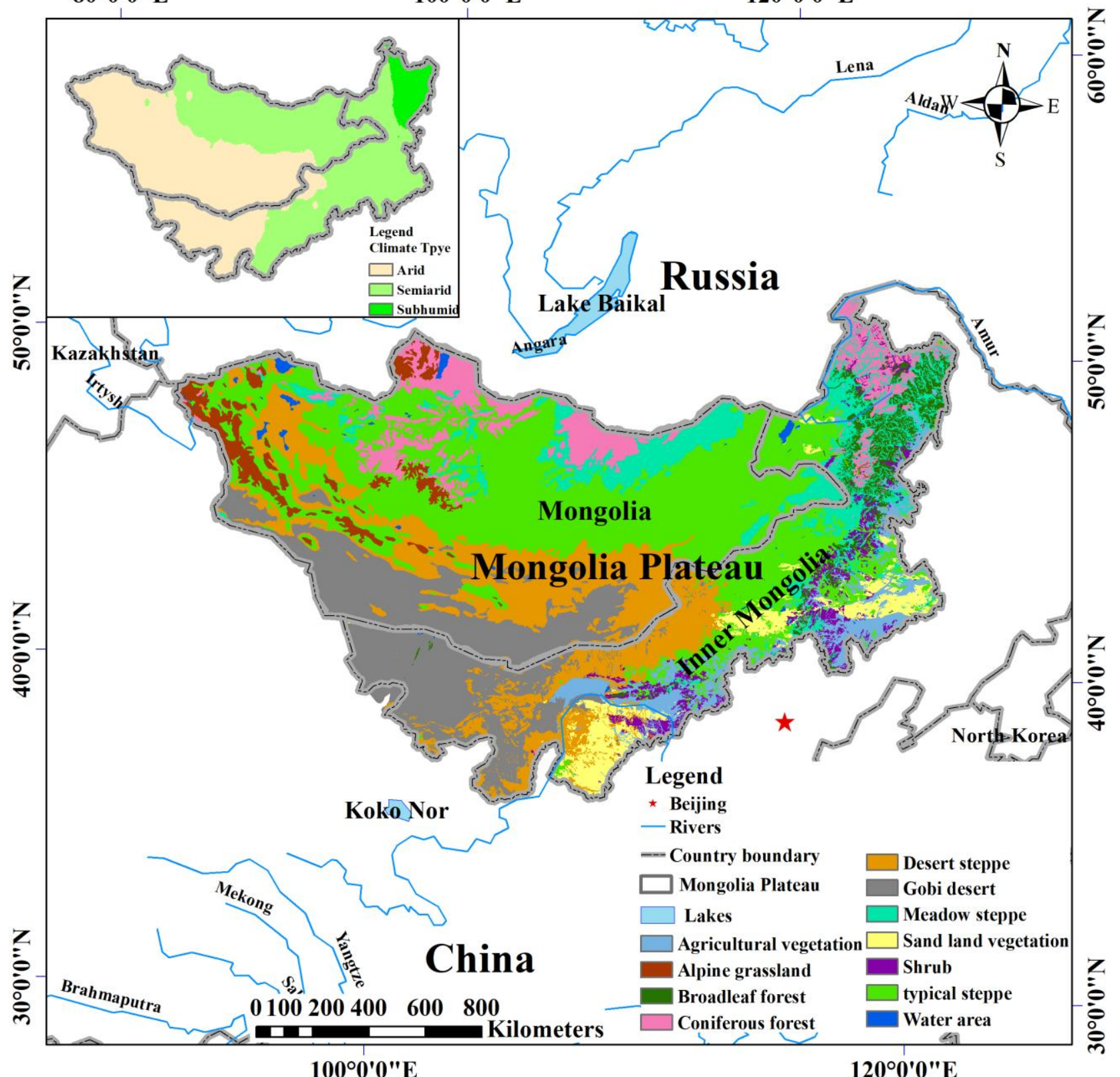

Figure 1. The study location, and the different vegetation and steppe types map of the Mongolian Plateau.

\subsection{Data Sources}

\subsubsection{The GIMMS NDVI3g V1.0 Dataset}

The GIMMS NDVI3g V1.0 dataset was developed by the National Aeronautics and Space Administration (NASA) based on the National Oceanic and atmospheric administrationadvanced very high resolution radiometer (NOAA-AVHRR) series data. This is a long-term global vegetation index (1981-2015), with a spatial resolution of $0.083^{\circ}$ and a temporal resolution of $15 \mathrm{~d}$. This long dataset was produced from two different sensors: the AVHRR/2 (July 1981 to November 2000); and the AVHRR/3 (from November 2000 to the present). This dataset eliminates the influence of atmospheric water vapour, volcanic eruptions, solar altitude angle, and sensor sensitivity, thereby effectively improving accuracy (further details in https: / / www.nasa.gov / nex/ (accessed on 23 December 2020)). We obtained the NDVI dataset from the NASA website [32]; this is a global dataset spanning from 1982-2015. MATLAB software was used to read, register, and convert the format and mask extraction for the research area. Then, the maximum synthesis method was used to extract the monthly 
and annual NDVI. As there are many types of vegetation in the Mongolian Plateau, the same ecosystem often contains multiple vegetation types in different natural belts, with some vegetation types showing obvious seasonal characteristics. To acquire a complete description of interannual vegetation activity, we analysed the NDVI characteristics at the pixel scale, and compared and analysed disparities between different vegetation areas.

\subsubsection{CCI-LC Products}

We used a time series of consistent Global Land Cover maps at a spatial resolution of $300 \mathrm{~m}$ from 1992 to 2015; these maps were produced by the European Space Agency (ESA) Climate Change Initiative (CCI).

\subsubsection{Climate Dataset}

The meteorological data used in this study was mainly comprised of PET, precipitation (PRE), maximum temperature (Tmax), minimum temperature (Tmin), mean temperature (Tem), and soil moisture (SM); all data spanned the 1981-2015 period. With the exception of data from CRU 4.04 at $0.5^{\circ}$ resolution, other climatic factors were derived from the TerraClimate dataset. These data were created using climatically aided interpolation, combining high spatial resolution climatological normals from the WorldClim versions 1.4 and 2 datasets. All data was at a monthly temporal resolution and a $\sim 4 \mathrm{~km}\left(1 / 24^{\circ}\right)$ spatial resolution [33]. To match the spatial resolution of the GIMMS NDVI3g V1.0, monthly climatic factors were interpolated to $0.083^{\circ}$ using the thin-plate smoothing spline method [34].

\subsubsection{Socioeconomic Dataset}

The socioeconomic data used in this study included the statistical numbers of livestock, human population (Pop), and gross domestic product (GDP) from 1982 to 2015. These datasets were obtained from the IMG Statistical Yearbook (1983-2016) and the Mongolian Statistical Information Service (http:/ / www.1212.mn/ (accessed on 23 December 2020)). Some data were also collected from the website https://www.kylc.com/ (accessed on 23 December 2020).

All data sources used in this study as shown in Table 1.

Table 1. List of data sources used in this study.

\begin{tabular}{|c|c|c|c|}
\hline Name & Time Scale & Spatial Scale & Data Sources \\
\hline GIMMS NDVI3g V1.0 & 1982-2015 & $0.083^{\circ}$ & $\begin{array}{c}\text { NASA } \\
\text { https:/ / ecocast.arc.nasa.gov/data/pub/gimms/3g.v1/ } \\
\text { (accessed on 23 December 2020) }\end{array}$ \\
\hline CCI-LC products & 1992-2015 & $300 \mathrm{~m}$ & $\begin{array}{c}\text { European Space Agency (ESA) Climate Change } \\
\text { Initiative (CCI) } \\
\text { http:/ / www.esa.int/ (accessed on } 23 \text { December 2020) }\end{array}$ \\
\hline $\begin{array}{c}\text { Potential evapotranspiration (PET) } \\
\text { Precipitation (PRE) } \\
\text { Maximum temperature (Tmax) } \\
\text { Minimum temperature (Tmin) } \\
\text { Soil moisture (SM) }\end{array}$ & 1981-2015 & $\sim 4-\mathrm{km}\left(1 / 24^{\circ}\right)$ & $\begin{array}{c}\text { TerraClimate dataset } \\
\text { http:/ / www.climatologylab.org/terraclimate.html } \\
\text { (accessed on 23 December 2020) }\end{array}$ \\
\hline Mean temperature (Tem) & & $0.5^{\circ}$ & $\begin{array}{c}\text { CRU4.04 } \\
\text { (http:/ / data.ceda.ac.uk/badc/cru/data/cru_ts/cru_ts_4. } \\
\text { 04/data (accessed on } 23 \text { December 2020)) }\end{array}$ \\
\hline $\begin{array}{l}\text { The numbers of livestock } \\
\text { Human population (Pop) } \\
\text { Gross domestic product (GDP) }\end{array}$ & 1982-2015 & National & $\begin{array}{l}\text { Inner Mongolia Statistical Yearbook (1982-2015)/ } \\
\text { Mongolian Statistical Information Service }\end{array}$ \\
\hline
\end{tabular}




\subsection{Methods}

\subsubsection{Linear Regression Method}

Linear regression was used to detect trends in the mean NDVI and climatic factors during the growing season (April-October). The F test was used to determine the significance of any trends; when $p<0.05$, a trend was considered significant. The linear trend for each pixel was calculated using MATLAB software.

\subsubsection{Breaks for Additive Season and Trend (BFAST) Method}

The BFAST is an additive decomposition model that was used to iteratively fit a piecewise linear trend and a seasonal model [35]. The general model is as follows:

$$
Y_{t}=T_{t}+S_{t}+e_{t}, t=1, \cdots \cdots n
$$

where $Y_{t}$ is the monthly NDVI from 1982-2015 in the Mongolian Plateau; $T_{t}$ is the trend component (Trend); $S_{t}$ is the seasonal component (seasonal); and $e_{t}$ is the remainder component (Remainder).

The long-term trend component, $T_{t}$, is piecewise linear with segment-specific slopes and intercepts on $m+1$ different segments. Thus, there are $m$ BPs, $\tau_{i-1}, \cdots \cdots \tau_{m}$ such that:

$$
T_{t}=\alpha_{i}+\beta_{i} t
$$

where $i=1,2, \cdots \cdots m$ and, we define $\tau_{0}=0$ and $\tau_{m+1}=n$. The order of magnitude of BPs, $M$, may be calculated using the intercepts, $\alpha_{i}$ and $\beta_{i}$, of the linear model, $T_{t}$, between $t_{i-1}$ and $t_{i}$, as follows:

$$
M=\left(\alpha_{i-1}-\alpha_{i}\right)+\left(\beta_{i-1}-\beta_{i}\right) t
$$

The seasonal component, $S_{t}$, is a piecewise harmonic model. When we define $t_{0}=0$ for $t_{j}<t \leq t_{j+1}$, the seasonal component may be fitted as follows:

$$
S_{t}=\sum_{k=1}^{j} \alpha_{j, k} \sin \left(\frac{2 \pi k t}{f}+\delta_{j, k}\right)
$$

where $j$ is the position of the BPs, $j=1, \cdots \cdots m$, with $m$ BPs in total; $k$ is the number of harmonic terms; $\alpha_{j, k}$ and $\delta_{j, k}$ are the segment-specific amplitude and phase, respectively; and $f$ is the frequency. The data for this study was derived from the monthly NDVI dataset for the 1982-2015 period, in which $f=12$.

For the long-term trend and seasonal components, the number of BPs and their positions in the time series were determined using the least squares method and Bayesian information criterion [36].

Prior to the BFAST detection process, we excluded non-vegetated pixels using vegetation and steppe-type maps on the Mongolian Plateau. This means that land cover classes including the "Lakes/Water area" and "Gobi desert" were omitted from the statistics using a masking procedure.

\subsubsection{Partial Correlation Analysis Method}

In multivariate correlation analysis, simple correlation coefficients may not truly reflect the relationship between variables due to a complex relationship that may be affected by more than one variable. As such, the partial correlation coefficient is a better choice. It is able to calculate the correlation coefficient between two variables while eliminating the influence of other variables. This study used the absolute value of the partial correlation coefficient to indicate the degree of correlation.

Partial correlation analysis was used to calculate the correlation coefficient determination in order to understand the impact of cumulative climatic factors on the mean growing season NDVI (NDVI $g_{g s}$ ) for 1982-2015 in the Mongolian Plateau. The results of this analysis ranges from -1 to +1 , indicative of either a negative or positive correlation, respectively. 
The partial correlation coefficients of the $\mathrm{NDVI}_{\mathrm{gs}}$ and the cumulative climatic factors at a one-to-twelve-month time scale were candidates to evaluate the cumulative effect of climatic factors on vegetation (Equation (5)). The cumulative effect of climatic factors on vegetation (Equation (6)) was based on the period of time with maximum coefficients, the cumulative time interval (e.g., how many months), and the correlation under the time interval. The general equation is as follows:

$$
\begin{gathered}
R_{i}=\text { partialcorr }\left(n d v i, c f_{i}\right) \\
R_{\text {accmax }-g s}=\max _{1 \leq i \leq 12}\left(R_{i}\right)
\end{gathered}
$$

where $R_{i}$ is the partial correlation coefficient between climatic factors on NDVI $\mathrm{gs}_{\text {s }}$ and climatic factors including PET, PRE, Tmax, Tmin, Tem, and SM; $i$ is the accumulated time from one to twelve months prior to the growing season for climatic factors; and $R_{a c c m a x}-g s$ is the maximum value of $R_{i}$. The partial correlation coefficient may be expressed as:

$$
\begin{gathered}
R_{j}=\text { partialcorr }\left(n d v i, c f_{j}\right) \\
R_{\max -g_{s}}=\max _{4 \leq j \leq 10}\left(R_{j}\right)
\end{gathered}
$$

where $R_{j}$ is the partial correlation coefficient between climatic factors and mean NDVI during the growing season; $j$ represents months from April to October; and $R_{\max -g_{s}}$ is the maximum value of $R_{j}$.

\subsubsection{Geographical Detector Model}

General geographical detectors include factor, interaction, risk, and ecological detectors. The factor detector reveals the relative importance of the explanatory variables [37]. The power of the determinants is computed using a Q-statistic:

$$
Q_{v}=1-\frac{\sum_{j=1}^{M}\left(N_{v, j}-1\right) \sigma_{v, j}^{2}}{\left(N_{v}-1\right) \sigma_{v}^{2}}
$$

where $N_{v}$ and $\sigma_{v}^{2}$ are the number and variance of the climatic factors within the entire Mongolian Plateau, respectively; and $N_{v, j}$ and $\sigma_{v, j}^{2}$ are the number and variance of climatic factors within the $j-$ th pixel, respectively, where $j=1, \cdots \cdots, M$.

The other core component is the interaction detector, which determines the interactive effect by comparing the $Q$ values of two single variables. The interactions explain whether the impacts of two spatial variables are weakened, enhanced, or independent. Therefore, the interaction detector result includes the $Q$ values of interactions and types of interaction effects. The types of interactions between two covariates include nonlinear-weakened, ni-variable weakened, bi-variable enhanced, independent, and nonlinear-enhanced [38]. The $\mathrm{R}$ software package was used to compute the interaction detector, which is available at https: / / cran.r-project.org/web/packages/GD/ (accessed on 23 December 2020).

\subsubsection{Residual Trends (RESTREND) Method}

The residual analysis method used in this study was proposed by Evans and Geerken [39]. The predicted NDVI was obtained through pixel-by-pixel regression analysis of vegetation and related climatic factors; this predicted NDVI is considered to represent the influence of climatic factors on NDVI. Then, subtracting the predicted NDVI from the observed NDVI by remote sensing removes the impact of climate signals and anthropogenic activity on vegetation cover changes, to determine the impact of the latter:

$$
\varepsilon=N D V I_{\text {true }}-N D V I_{\text {prediction }}
$$


where $\varepsilon$ is the RESTREND value; $N D V I_{\text {true }}$ is the observed NDVI; and NDVI $I_{\text {prediction }}$ is the predicted NDVI using the multivariate linear regression (MLR) method [40].

\subsubsection{Stepwise Multiple Regression Model}

A stepwise multiple regression model was used to identify drivers of interannual climatic variability and anthropogenic activity affecting the mean growing season NDVI $\left(\mathrm{NDVI}_{\mathrm{gs}}\right)$ in the Mongolian Plateau. The determined regression and predictor are represented by Equation (11):

$$
\mathrm{NDVI}_{\mathrm{gs}} \sim \mathrm{PET}+\mathrm{PRE}+\mathrm{SM}+\mathrm{Tem}+\mathrm{Tmax}+\mathrm{Tmin}+\mathrm{GDP}+\text { Pop + Livestock }
$$

A relative importance analysis based on the multiple regression frameworks of these combined variables indicated the strength of each predictor in relation to the $\mathrm{NDVI}_{\mathrm{gs}}$ for the Mongolian Plateau (1982-2015). The LMG, Genizi, First, and CAR models were applied to reduce the uncertainty of impacts from different factors [41]. All models were bootstrapped using 1000 replicates, producing 95\% confidence intervals [42]; this method was calculated using the R package "relaimpo" [41].

\section{Results}

\subsection{Long-term Changes in Different Climatic Factors}

The trends and slopes in the temporal variation of different climatic factors during the growing season of 1982-2015 in the Mongolian Plateau were detected via the linear regression method (Figure 2). Figure 2 shows that PRE and SM exhibited a statistically significant negative trend in variability of -10.48 and $-1.19 \mathrm{~mm} /$ decade, respectively $(p<0.05$; Figure 2a,c). In line with global warming, an apparent warming trend was evident in the Mongolian Plateau; the mean temperature showed a significant long-term warming trend of $0.47^{\circ} \mathrm{C} /$ decade $(p<0.05$; Figure $2 \mathrm{~d}$ ). According to the NOAA 2019 Global Climate Summary, the combined land and ocean temperature has increased at an average rate of $0.07^{\circ} \mathrm{C}$ per decade since 1880 . However, the average rate of temperature increase in the Mongolian plateau has been $0.18^{\circ} \mathrm{C}$ per decade since 1981 ; this is much faster than the average global warming trend [43]. Warming was attributed to an increase in $T_{\min }$ and $T_{\text {max }}$, showing a significant long-term warming trend of 0.47 and $0.48{ }^{\circ} \mathrm{C} /$ decade, respectively. This temperature increase implies a significant increase in PET over the long-term (Figure $2 \mathrm{~b})$, with a trend of $2.99 \mathrm{~mm} /$ decade $(p<0.05)$.

For the entire region, the multiyear averaged PRE and SM were decreasing from the northeastern to southwestern parts of the Mongolia Plateau, while the spatial distribution of the other four meteorological factors was reversed (Figure S1). The distribution of climatic factors showed a strong spatial gradient (Figure 3). The results show an entire region undergoing a warming trend, in which the average temperature is significant increasing in all pixels. The lower trend values of PET, Tem, Tmax, and Tmin on the southeastern Mongolian Plateau and lower trend values of PRE and SM on the northeastern Mongolian Plateau, which spans $89.56 \%$ and $73.79 \%$ of pixels, respectively, were all generally decreasing. 

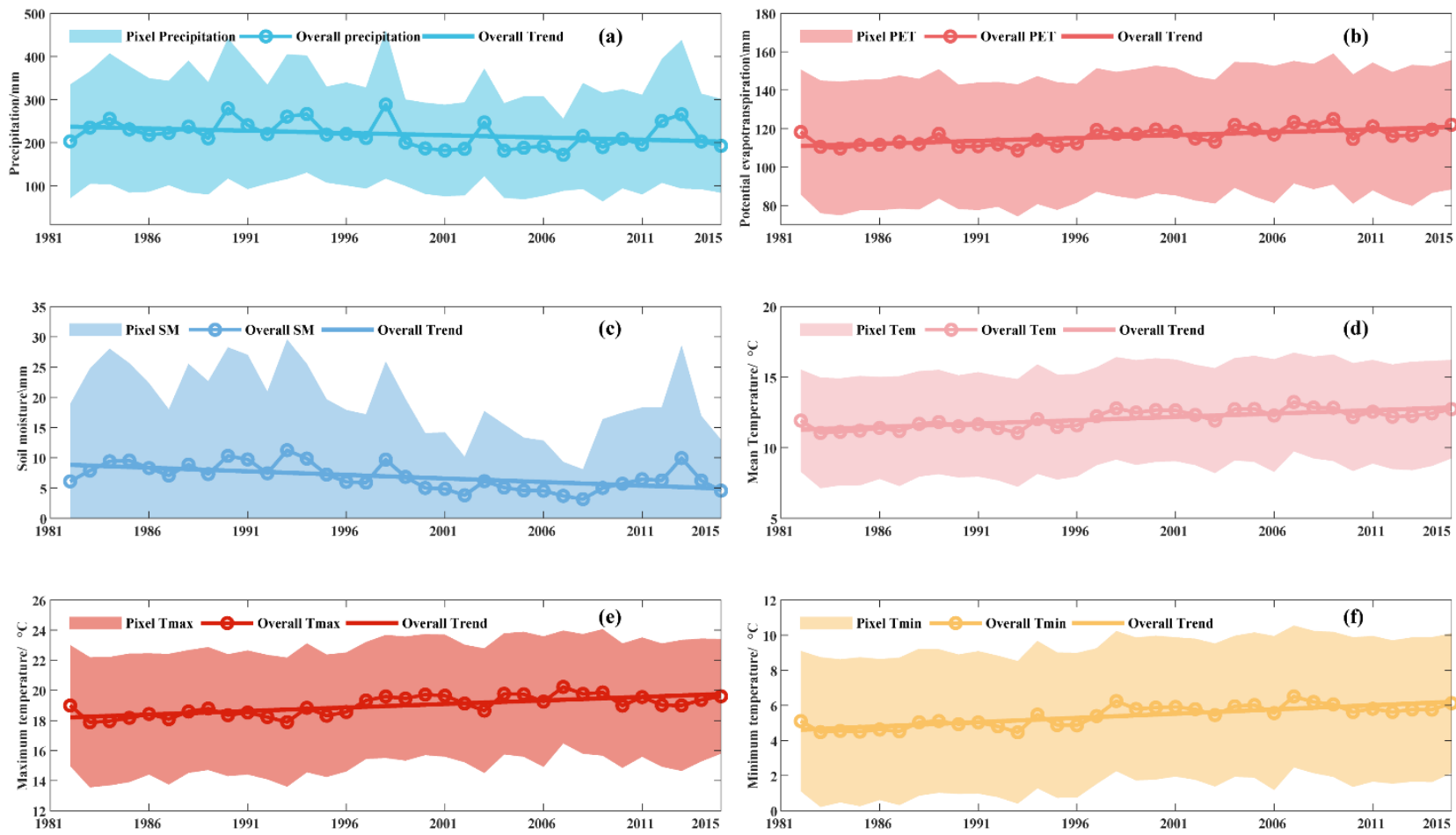

Figure 2. Long-term changes in different climatic factors during the growing season of 1982-2015 in the Mongolian Plateau. (a) PRE, (b) PET, (c) SM, (d) Tem, (e) Tmax, (f) Tmin. Coloured strips highlight sem/std, where sem is standard error of mean and SD is standard deviation of climatic factors.

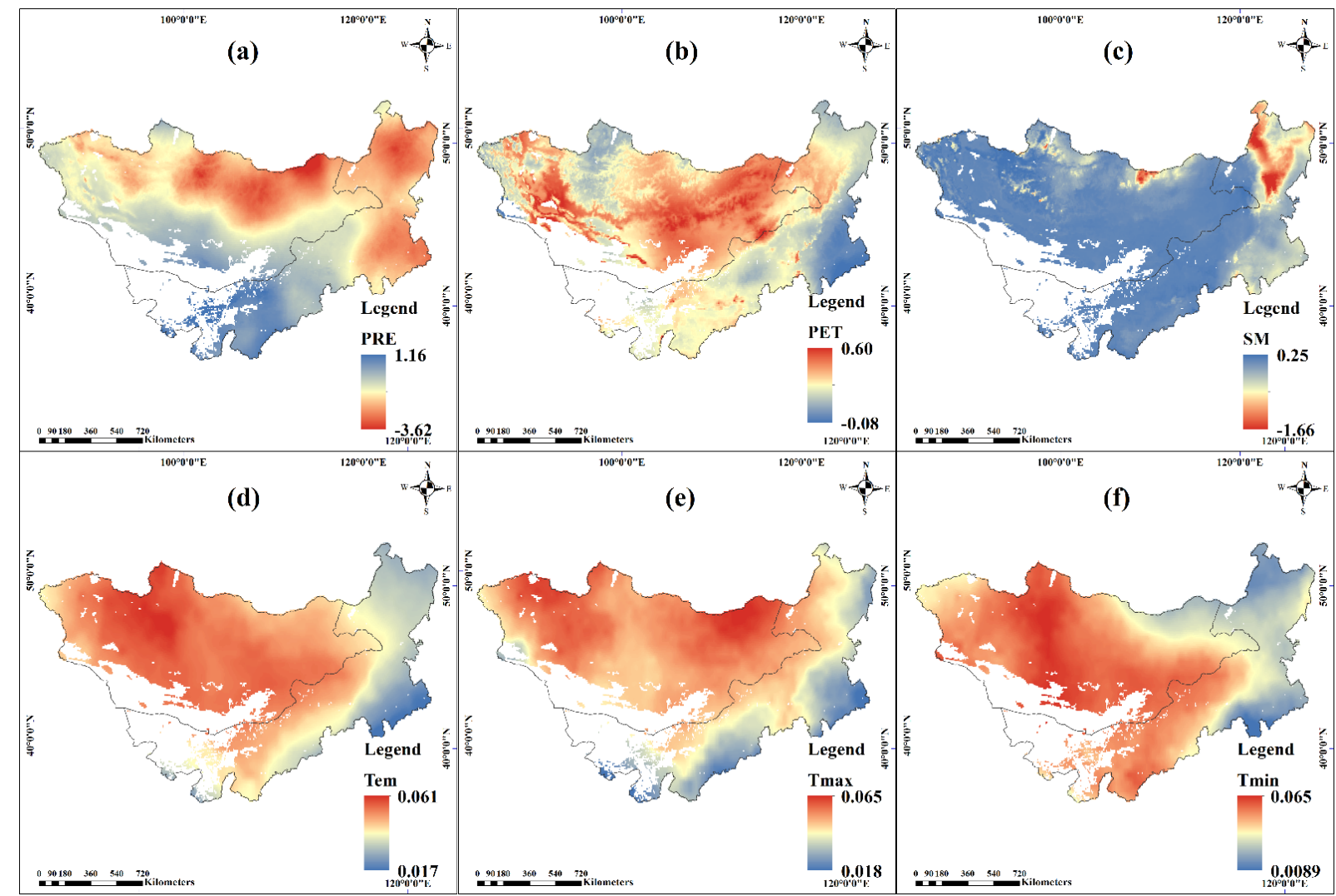

Figure 3. Spatial trends distribution of climatic factors during the growing season of 1982-2015 in the Mongolian Plateau. (a) PRE, (b) PET, (c) SM, (d) Tem, (e) Tmax, (f) Tmin. 


\subsection{Abrupt Changes in Vegetation Dynamics}

Increasingly intense anthropogenic activity and natural variability from climate change will lead to abrupt changes in vegetation. As such, we focused on the detection and characterisation of such changes within the trend component of the monthly NDVI time series for different vegetation and steppe types in the Mongolian Plateau. BFAST was used to identify shifts in monthly NDVI for the different vegetation and steppe types of the Mongolian Plateau (Figure 4). There was a clear fluctuation in the NDVI and an overall increasing trend from 1982 to 2015 . The monthly NDVI of desert steppe, scrub, and agricultural vegetation had three BPs, in which the desert steppe experienced a statistically insignificant increase, a significant increase $\left(0.0047 \mathrm{y}^{-1}\right)$, and an insignificant decrease. The BP years were 1988 and 1994. There was a statistically insignificant decrease at a rate of $-0.0001 \mathrm{y}^{-1}$ in the NDVI for the desert steppe after the BP year. This indicates that the steppes have been degraded by climate change and anthropogenic activity in the last 20 years. Scrub and agricultural vegetation experienced BPs in 2009 and 2015, respectively. These BPs included a statistically significant, insignificant and significant increase, in which the growth rate of NDVI decreased significantly from 1999-2009; this generated an overall increasing trend characterised by a high-low-high pattern. For broadleaf forests, there was no BP, and the overall decreasing slope was almost zero. This indicates that the broadleaf forests of the Mongolian Plateau are relatively stable under the influence of natural and anthropogenic factors. Coniferous forests, meadow steppe, and the typical steppe experienced a BP in 2002, although they all showed an increase in the NDVI before and after the $\mathrm{BP}$. The increase to the NDVI in coniferous forests became smaller after the BP, while the growth rate of meadow steppe changed from being statistically insignificant to significant, in which the rate of change increased from 0.0007 to $0.0023 \mathrm{y}^{-1}$. The NDVI trend for sand land vegetation increased from 0.0004 to $0.0025 \mathrm{y}^{-1}$, and alpine steppe experienced a BP in 1993 , from a statistically insignificant increase to an insignificant decrease $\left(-0.0005 \mathrm{y}^{-1}\right)$. Overall, the changes to the NDVI showed significant spatial heterogeneity for different vegetation types in the region due to the spatial variability in anthropogenic activity and climatic factors.

Spatial variability ceases when we focus on the subregion, due to the diversity of vegetation types over the Mongolian Plateau. As such, we also counted the numbers of BFAST detected BPs for the proportion of total and specific land cover areas (\%) for different vegetation and steppe types between 1982 and 2015; the statistical results are detailed in Tables 2 and 3. The results show that the number of abrupt trend-shifts that were detected varied from zero to four at the pixel scale. In total, the area fraction of BPs made up $69.58 \%$ of the entire Mongolian Plateau, while $39.95 \%$ of pixels had one BP that accounted for $57.42 \%$ of the total number of BPs. The typical and desert steppes with one or more BPs accounted for $29.38 \%$ and $13.82 \%$ of the Mongolian Plateau, while $74.9 \%$ and $70.34 \%$ of both vegetation types had one or more BPs, respectively. In particular, $30.41 \%$ of desert steppe had two BPs, while $12.27 \%$ of desert steppe pixels had three BPs; these results indicate that desert steppe has been affected by significant anthropogenic activity or climate change. For the shrub vegetation type, the BFAST detected BPs accounted for $2.16 \%$ of this type. However, $79.47 \%$ of the shrub pixels had one or more BPs; this was the highest percentage of all the vegetation and steppe types. This means that the shrub type has also been affected by significant anthropogenic activity or environmental conditions. For alpine steppe, broadleaf, and coniferous forests, the proportion of BPs was small for the overall population; however, each of these types have experienced a relatively lower intensity impact from climate change and anthropogenic activity than other areas. 
(a): Coniferous forest

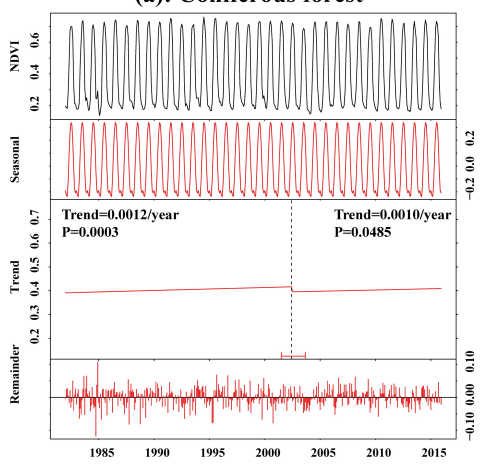

(d): Typical steppe

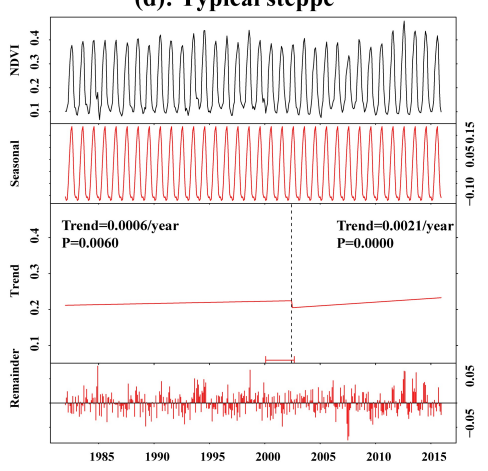

(g): Sand land vegetation

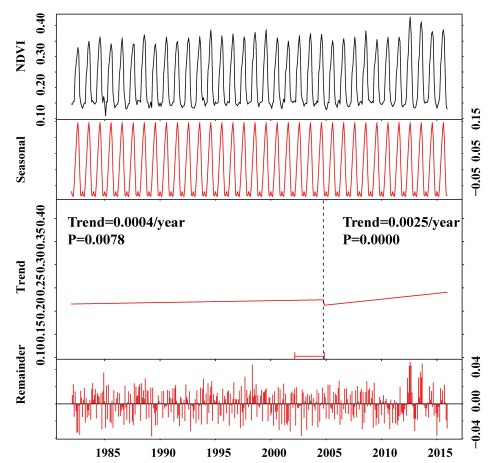

(b): Broadleaf forest

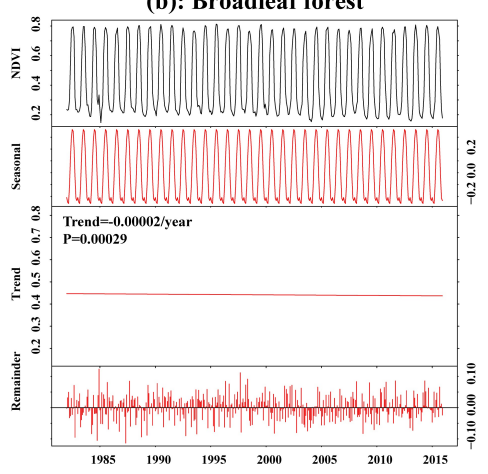

(e): Desert steppe

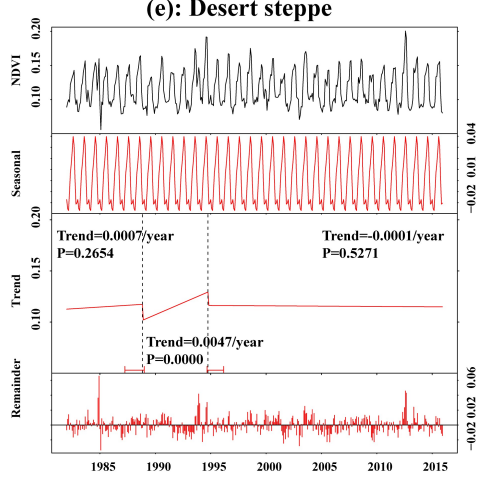

(h): Agricultural vegetation

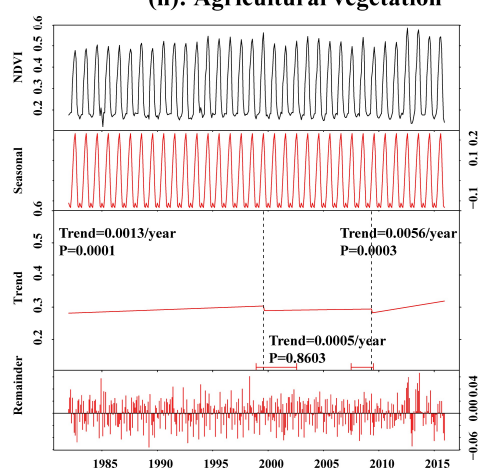

(c): Meadow steppe

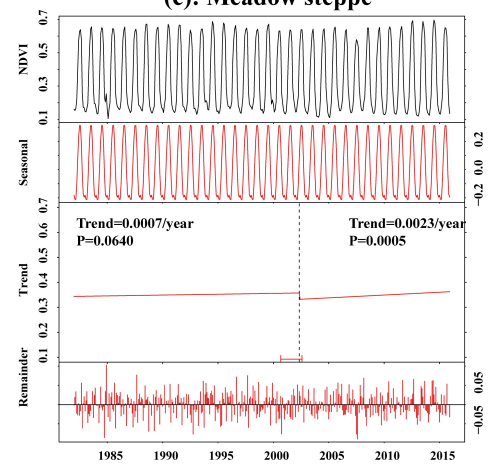

(f): Shrub

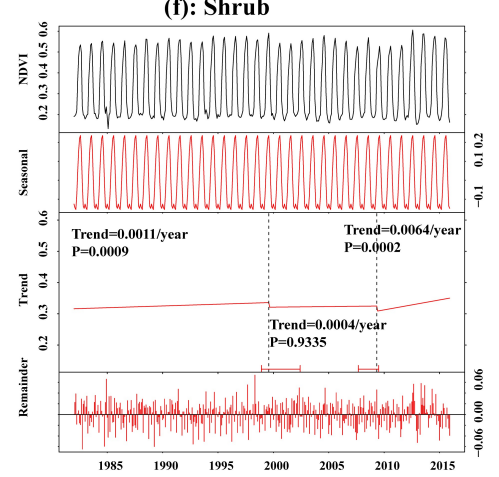

(i): Alpine steppe

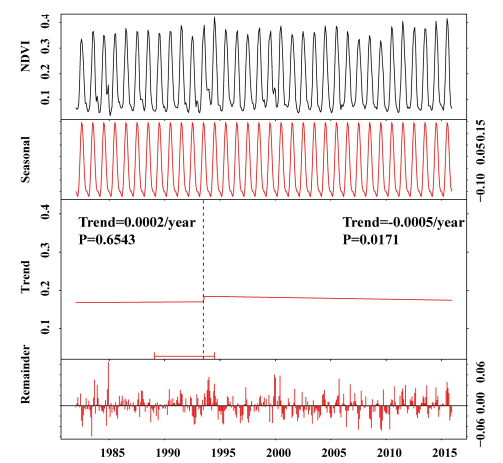

Figure 4. Abrupt breaks for additive seasonal and trend method (BFAST)-detected shifts in monthly NDVI for 19822015 in the different vegetation and steppe types of the Mongolian Plateau. (a) Coniferous forest, (b) Broadleaf forest, (c) Meadow steppe, (d) Typical steppe, (e) Desert steppe, (f) Shrub, (g) Sand land vegetation, (h) Agricultural vegetation, (i) Alpine steppe.

Table 2. Percentage of the total area for all vegetation and steppe types in the Mongolian Plateau, split by the number of breakpoints (BPs) detected between 1982 and 2015 .

\begin{tabular}{lcccccc}
\hline \multicolumn{1}{c}{ Types } & $\mathbf{0}$ & $\mathbf{1}$ & $\mathbf{2}$ & $\mathbf{3}$ & $\mathbf{4}$ & 1 or More Breakpoints \\
\hline Meadow steppe & 4.00 & 5.42 & 1.87 & 0.18 & 0.02 & 7.49 \\
Typical steppe & 9.85 & 16.64 & 10.00 & 2.39 & 0.35 & 29.38 \\
Alpine steppe & 1.71 & 1.11 & 0.70 & 0.36 & 0.04 & 2.21 \\
Shrub & 0.56 & 1.48 & 0.61 & 0.07 & 0.00 & 2.16 \\
Desert steppe & 5.83 & 5.04 & 5.98 & 2.41 & 0.40 & 13.82 \\
Broadleaf forest & 1.61 & 1.12 & 0.55 & 0.04 & 0.00 & 1.71 \\
Agricultural & 1.37 & 3.18 & 1.06 & 0.08 & 0.00 & 4.32 \\
vegetation & & & & & & 3.31 \\
Sand land & 1.08 & 2.82 & 0.45 & 0.04 & 0.00 & 5.17 \\
vegetation & 4.41 & 3.15 & 1.88 & 0.12 & 0.02 & 69.58 \\
Coniferous forest & 30.42 & 39.95 & 23.10 & 5.70 & 0.83 & \\
Total & & & & & & \\
\hline
\end{tabular}


Table 3. Percentage of the specific land cover area for the different vegetation and steppe types, split by the number of breakpoints detected between 1982 and 2015.

\begin{tabular}{lcccccc}
\hline \multicolumn{1}{c}{ Types } & $\mathbf{0}$ & $\mathbf{1}$ & $\mathbf{2}$ & $\mathbf{3}$ & $\mathbf{4}$ & 1 or More Breakpoints \\
\hline Meadow steppe & 34.84 & 47.13 & 16.27 & 1.58 & 0.18 & 65.16 \\
Typical steppe & 25.1 & 42.43 & 25.5 & 6.08 & 0.89 & 74.9 \\
Alpine steppe & 43.63 & 28.25 & 17.77 & 9.28 & 1.06 & 56.36 \\
Shrub & 20.53 & 54.35 & 22.54 & 2.58 & 0 & 79.47 \\
Desert steppe & 29.67 & 25.62 & 30.41 & 12.27 & 2.04 & 70.34 \\
Broadleaf forest & 48.59 & 33.65 & 16.59 & 1.17 & 0 & 51.41 \\
Agricultural & 24.04 & 55.94 & 18.56 & 1.46 & 0 & 75.96 \\
vegetation & & & & & & 75.36 \\
Sand land & 24.65 & 64.13 & 10.34 & 0.89 & 0 & 53.99 \\
vegetation & 46.01 & 32.9 & 19.65 & 1.25 & 0.19 & \\
Coniferous forest & & & & & &
\end{tabular}

For the entire region, the multiyear averaged $\mathrm{NDVI}_{\mathrm{gs}}$ was decreasing from the northeastern to southwestern Mongolia Plateau; this is consistent with the distribution of climatic factors and terrestrial characteristics. The spatial distribution of the variations in NDVI $\mathrm{Ng}_{\mathrm{gs}}$ for 1982-2015 as per the linear regression method is shown in Figure S2b,c. The results show that $71.16 \%$ of pixels experienced an increase in the $\mathrm{NDVI}_{\mathrm{gs}}$, particularly in eastern Mongolia and the southern border of IMG. The statistical results show that $37.67 \%$ of pixels showed significant growth, with only $7.15 \%$ of the pixels exhibiting a significant decrease. Vegetation changes on the Mongolian Plateau were impacted by the compounding effects of human activity and climatic factors, such as wildfire and grazing [44,45]. The BFAST method provides functionality to detect stable yet abnormal changes from historical trends in the monthly NDVI. The results show that the years experiencing abrupt changes were distributed from 1987 to 2010, with a total of 40989 BPs. Overall, the NDVI on the Mongolian Plateau initially experienced widespread abrupt changes in 1993, accounting for $8.70 \%$ of the total number of one or more BP pixels; these abrupt changes also occurred in 2002 and 2003. Many areas experiencing abrupt changes were identified in Mongolia, accounting for $6.70 \%$ and $8.85 \%$ of the total number of pixels, respectively. There were also many areas experiencing abrupt changes in NDVI every year until 2010, where they reached a peak of $9.63 \%$. Further analysis revealed that most areas experiencing abrupt changes in 1993 were found in Mongolia, followed by those in 2010 (2794 pixels). In contrast, IMG had the highest percentage of abrupt changes in 2003, followed by 2006 and 2007. Overall, 1993, 2003 , and 2010 were the years predominantly experiencing abrupt changes.

The spatial distribution of trend changes before and after BPs for 1982-2015 on the Mongolian Plateau is shown in Figure 5. BFAST detected trend variations with no BPs accounted for $30.42 \%$ of pixels; these areas were mainly located in the middle (Xilin Gol grassland) and northeastern (Hulunbuir grassland) IMG, China, and northwestern Mongolia (Figure 5a). These areas were mainly comprised of typical steppe, desert steppe, and coniferous forests. Figure $5 \mathrm{~b}, \mathrm{c}$ show the spatio-temporal distribution and variations of NDVI before and after one BP, respectively. There were 16 variations, and the "increased significantly-increased significantly" variation reached up to $26.93 \%$ of the total number. Following the BP, $71.34 \%$ of pixels showed an increasing trend, in which this trend was statistically significant for $77.74 \%$ of those pixels. The mean variation of NDVI changed from $4.450 \times 10^{-4}$ to $2.708 \times 10^{-3} \mathrm{y}^{-1}$; the variation after the BP was approximately six times greater than before the BP. This means that after the changepoint years, the vegetation in northeastern Mongolia and east of central IMG is improving. This may be partially attributable to the positive efficacy of the Three-North Shelter Forest Program [46]. Figure $5 \mathrm{~d}-\mathrm{f}$ shows that of the BFAST detected trend variations with two BPs or more, the majority were located in Mongolia, including $85.26 \%$ and $95.55 \%$ of pixels with three and four BPs, respectively. In particular, northwestern Mongolia showed a northwest-southeast oriented strip, indicating that vegetation has been significantly affected at different times in this region, resulting in frequent variations in vegetation. 


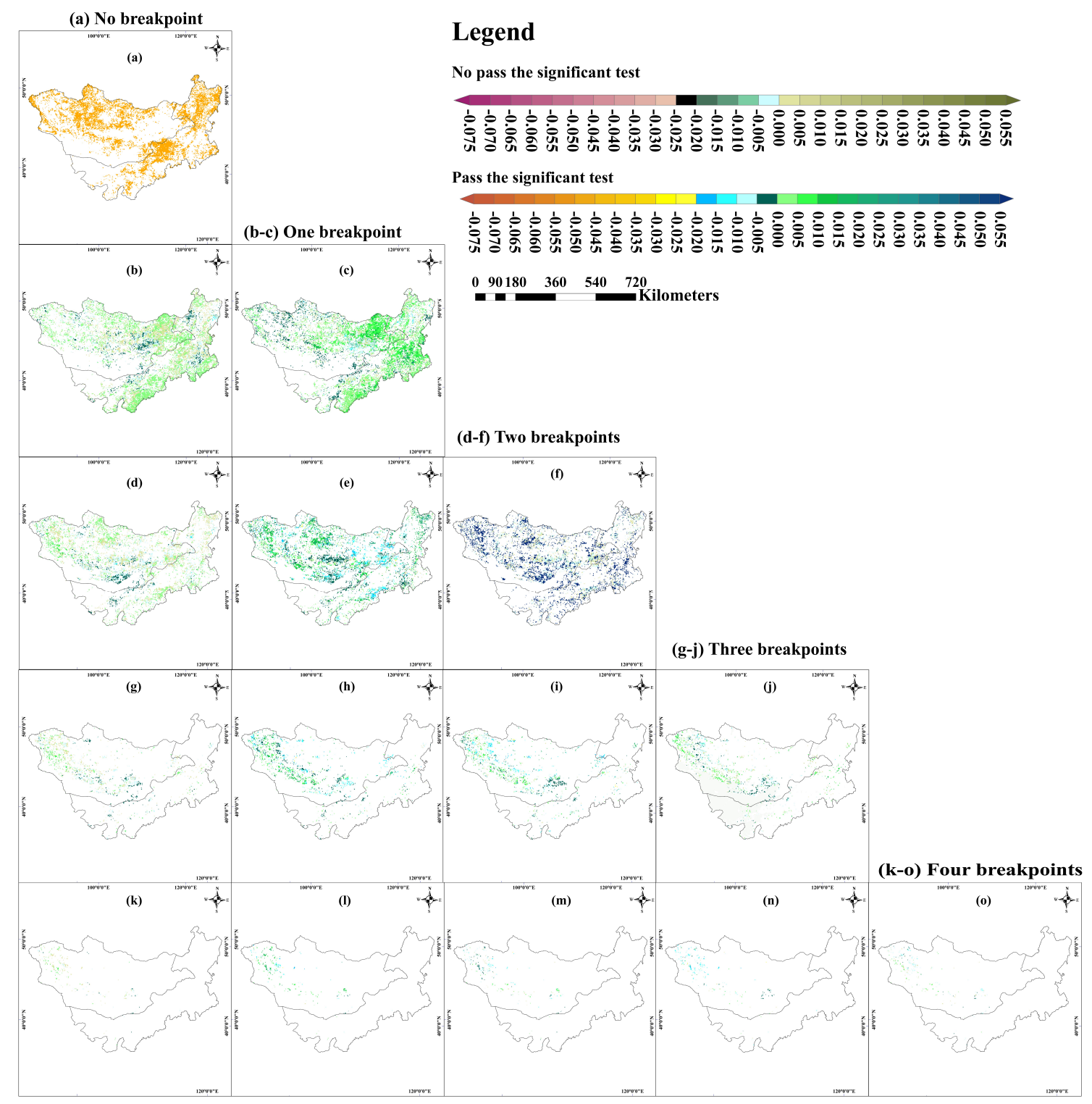

Figure 5. BFAST detected shifts in the NDVI trend before and after the breakpoints for 1982-2015 in the Mongolian Plateau. (a) no breakpoint, $(\mathbf{b}-\mathbf{c})$ one breakpoint, $(\mathbf{d}-\mathbf{f})$ two breakpoints, $(\mathbf{g}-\mathbf{j})$ three breakpoints, $(\mathbf{k}-\mathbf{o})$ four breakpoints.

\subsection{Vegetation Responses to Climate Change}

3.3.1. Vegetation Responses to Interannual Climate Change during the Growing Season

Figure 6 quantifies of the partial correlation coefficients between climatic factors and NDVI $g$ from 1982 to 2015. These coefficients offer a better understanding on the magnitude of influence on NDVI from changes in meteorological factors during the growing season. The results show that the partial correlations between mean NDVI $\mathrm{gs}_{\mathrm{g}}$ and PRE signified a spatially reversed relationship with other factors, with $75.01 \%$ of pixels $(37.49 \%$ of pixels were statistically significant) that were positively correlated with mean NDVI gs. This was mainly distributed in the central part of the Mongolian Plateau, while the coniferous forest and broadleaf forests in north-central Mongolia and eastern IMG were negatively correlated (Figure 6a). This is consistent with the results of Guo et al. [47] who reported a negative correlation between the corresponding PRE and NDVI $_{g s}$ in relatively colder regions. This was also partly confirmed by Fang et al. [48], who found that forest growth tended to decrease with increasing PRE under relatively cold conditions. Positive correlations between PRE and $\mathrm{NDVI}_{\mathrm{gs}}$ were also found in the desert steppe ( $97.76 \%$ of pixels; 
$68.47 \%$ statistically significant), sand land vegetation $(94.44 \%$ of pixels; $41.96 \%$ statistically significant), and the typical steppe (93.84\% of pixels; $65.35 \%$ statistically significant). PET and mean $\mathrm{NDVI}_{\mathrm{gs}}$ were negatively correlated in the western part of Mongolia and central IMG, accounting for $55.97 \%$ of pixels (Figure $6 \mathrm{~b}$ ). PRE and mean $\mathrm{NDVI}_{\text {gs }}$ were positively correlated; however, there was a negative correlation with PET during the growing season. This means that PRE was the primary factor for vegetation growth, while PET was the competing factor, generally reducing water availability [49]. Regions of high latitude and those in the southwest showed negative correlations, which may be related to higher temperatures accelerating snow melt [50] and increased PRE in the southwestern region. SM was the dominant driver of dry stress across ecosystem production [51]. We found that this factor accounted for $43.39 \%$ of pixels in which a negative correlation was observed (Figure 6c). This was particularly the case for the coniferous (64.93\%) and broadleaf forests $(56.96 \%)$, which may be related to the high-water demand of vegetation [52]. Figure $6 \mathrm{~d}$ shows that there were $59.16 \%$ pixels with a positive correlation between Tem and mean $\mathrm{NDVI}_{\mathrm{gs}}$, as per partial correlation analysis. This was particularly the case for coniferous $(81.92 \%)$ and broadleaf forests $(63.54 \%)$. This signifies the occurrence of amplified vegetation growth due to a faster warming rate than the warming rate at low latitudes. The mean $\mathrm{NDVI}_{\mathrm{gs}}$ increased in $70.74 \%$ of the sand land vegetation, which along with $94.44 \%$ pixels of PRE, showed an increasing trend. This conclusion is consistent with the relatively closer relationship between the temperate desert steppe and PRE than temperature [49]. Additionally, the optimal combination of water and heat conditions increased vegetation growth, while $53.29 \%$ and $63.96 \%$ of Tmax and Tmin pixels, respectively, were positively correlation with mean $\mathrm{NDVI}_{\mathrm{gs}}$, and demonstrated spatial consistency in Figure $6 \mathrm{~d}$. This illustrates that the decrease in diurnal temperature difference had a clear positive effect on vegetation growth.

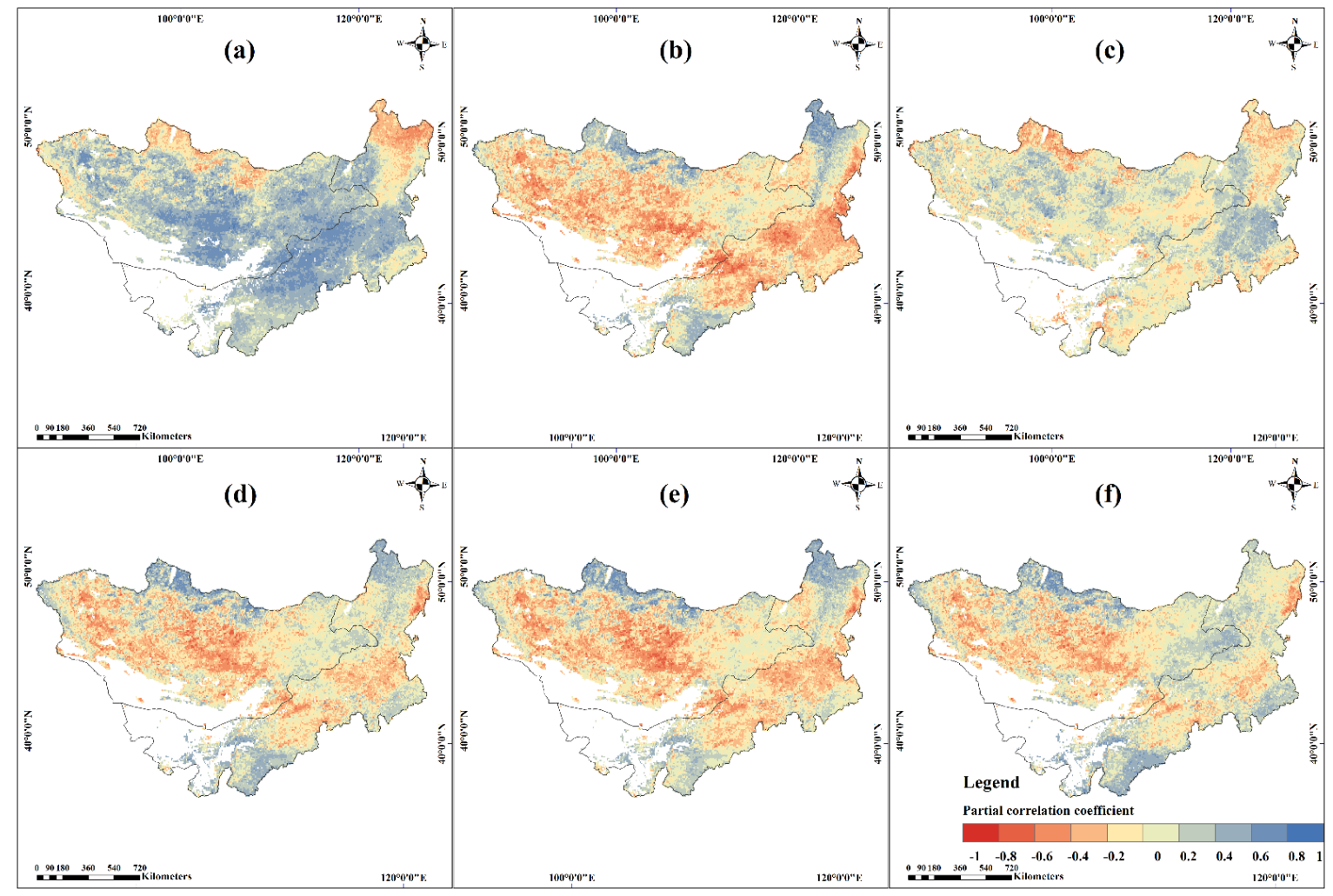

Figure 6. Spatial distribution of partial correlation coefficients between climatic factors and mean NDVI during the growing season of 1982-2015 in the Mongolian Plateau: (a) PRE, (b) PET, (c) SM, (d) Tem, (e) Tmax, (f) Tmin. 
The spatial heterogeneity of correlation between climatic factors and NDVI $\mathrm{gs}_{\mathrm{gs}}$ represents a general characteristic. Figure 7 presents the variation in the annual NDVI $\mathrm{gs}_{\mathrm{gs}}$ with the aridity index (AI) in order to investigate the heterogeneity of NDVI with gradient change at spatial scale. The AI is a simple and convenient numerical indicator of aridity based on long-term climatic water deficits; it is equal to the PRE/PET ratio. We calculated the annual mean $\mathrm{AI}$ and determined the aridity conditions of the region based on four pre-determined climatic categories: arid $(0<\mathrm{AI}<0.2)$; subhumid $(0.2 \leq \mathrm{AI}<0.5)$; semiarid $(0.5 \leq \mathrm{AI}<0.65)$, and humid $(\mathrm{AI} \geq 0.65)$. The results show that dry conditions significantly affect vegetation dynamics; the wetter the conditions, the better vegetation growth. As such, the highest NDVI values were mainly located in the subhumid zone (Figure $7 \mathrm{~b}$ ). However, the annual $\mathrm{NDVI}_{\mathrm{gs}}$ of the vegetation and steppe types showed homologous oscillations in three of the climatic categories. The lowest oscillations for the $\mathrm{NDVI}_{\mathrm{gs}}$ occurred in the subhumid zone, ranging from 0.40 to 0.70 . The $\mathrm{NDVI}_{\mathrm{gs}}$ of the semiarid zone ranged from 0.00 to 0.78 , and demonstrated the highest degree of oscillation; as such, except for vegetation itself, dry and wet conditions, also led to the oscillation of NDVI.

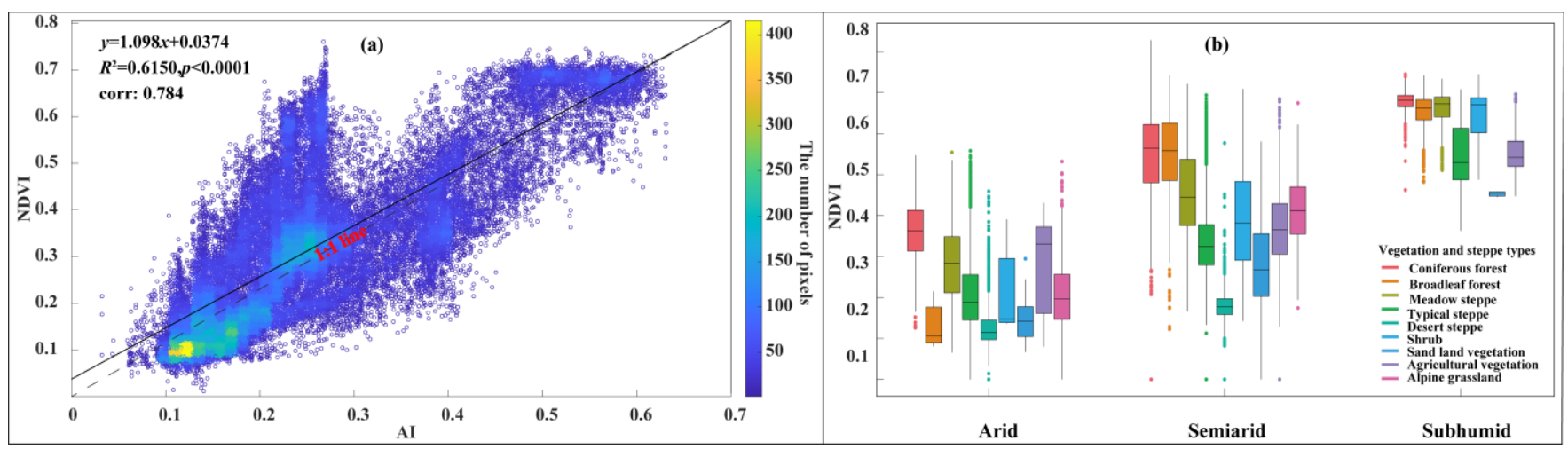

Figure 7. Variations in the annual NDVI $\mathrm{gs}_{\mathrm{s}}$ in relation to the aridity index in the Mongolian Plateau. (a) the heatscatter plot of AI and NDVI, (b) the boxplot of NDVIgs for different vegetation and steppe types in sub climate regions.

The geographical detector model was applied to clarify any correlations between climatic factors and mean NDVI (including non-linear relationship) during the growing season of 1982-2015 from a spatial heterogeneity perspective. Figure 8a shows the rank contributions of climatic factors on the $\mathrm{NDVI}_{\mathrm{gs}}$ using the factor detector; the PRE had the highest $Q$ value compared with the other climatic factors This which means that PRE is the most important climatic factor, while the second most important variable was SM. The remaining four climatic factors were far less important for NDVI than PRE and SM. The interaction detector was used to compare the sum contribution of two individual climatic factors, with the contribution of two attributes when combined together (Figure 8b). The results showed that the interaction between variables demonstrate a bi-variable enhancement pattern, without uni-variable weakening, independent or nonlinear-enhancement conditions; this means that bi-variable enhancement occurred from the interaction. The interaction between PRE and TEM had the highest combined $Q$ value (0.8921). This interaction was the major interactive variables affecting vegetation change in the study area, followed by $\operatorname{Tmax}(\mathrm{Q}=0.8874)$ and $\operatorname{Tmin}(\mathrm{Q}=0.8844)$. The $\mathrm{Q}$ values of $\mathrm{SM}$ and PET, SM and TEM, SM and Tmax, and PRE and SM, exceeded 0.8. We observed robust drier-hotter conditions under strengthened soil moisture-temperature coupling over Mongolia and northern China [53]; the results from the geographical detector were also consistent with this observation. 
(a) Factor detector

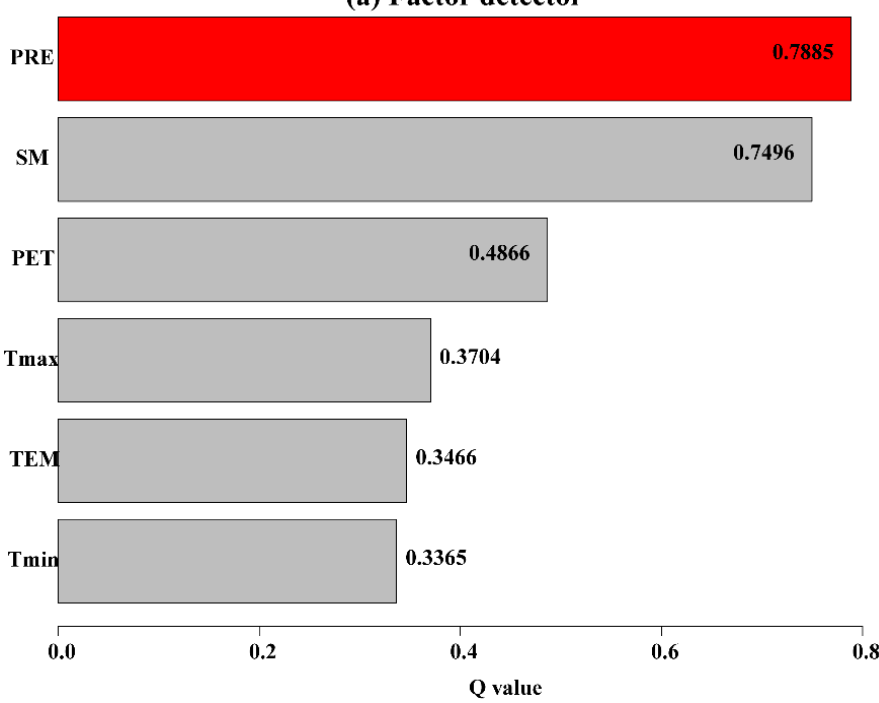

(b) Interaction detector

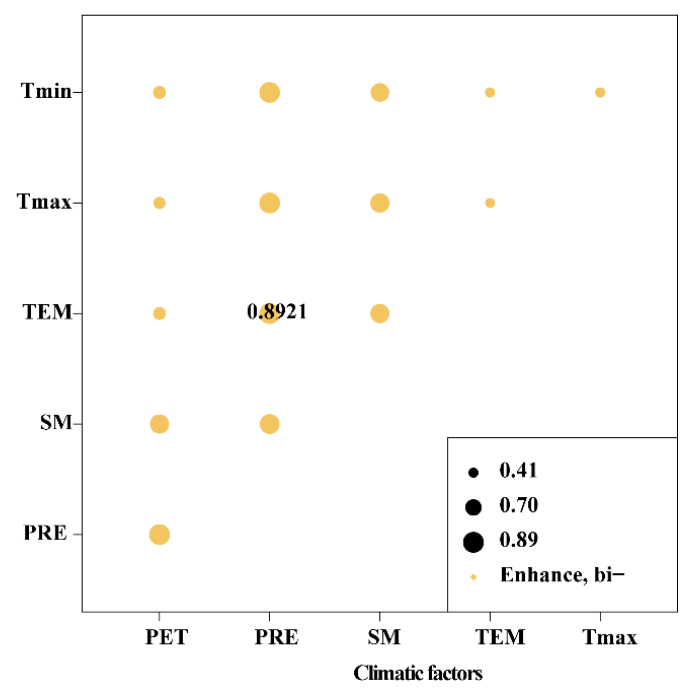

Figure 8. Results of (a) factor detector; and (b) interaction detector between climatic factors and mean NDVI during the growing season of 1982-2015 in the Mongolian Plateau.

\subsubsection{Spatial Patterns of the Cumulative Effects of Climate Change on NDVI}

Vegetation is affected by the SM deficit and hydrothermal conditions during the growing season. As such, the soil water content is related to climatic variations throughout the month, and the degree of influence from early climatic changes on SM, such as high PRE and low PET conditions. This may cause the soil to remain wet over a long period of time, which may ultimately be beneficial to vegetation growth [54]. This indicates that the NDVI usually experiences stronger cumulative effects from climate change. To investigate the response of vegetation to cumulative climate change, we focused on how the effects of longterm climate change were most likely to control vegetation growth. We and screened out the preceding months when meteorological drivers were likely to have a larger influence on vegetation. Based on the partial correlation analysis method, the cumulative effects of climatic factors on $\mathrm{NDVI}_{\mathrm{gs}}$ was estimated using the month with the largest correlation coefficient $\left(R_{\text {accmax }-g s}\right)$. Figure 9 presents the results, demonstrating that $99.75 \%$ of pixels occur when a large number of rainfall events promote vegetation growth. This includes $75.67 \%$ of pixels exhibiting a significant growth promotion (at a significance level of $95 \%$, as shown in Figure $9 \mathrm{~b}$ ). Most of $R_{\text {accmax }}$-gs time is concentrated in 1-6 months, particularly in January (13.54\% of pixels at a significance level of $95 \%)$, April $(22.06 \%$ of pixels at a significance level of $95 \%$ ), and May (20.87\% of pixels at a significance level of $95 \%)$. This means that the amount of PRE in early spring may affect the greening-up of vegetation, and the amount of snowfall in winter affects SM. In turn, this impacts on vegetation growth, whereby pixels affected over a long period of time were mainly concentrate in the high latitude regions. The $R_{a c c m a x-g s}$ for PET was positively correlated with $\mathrm{NDVI}_{\mathrm{gs}}$ up to $79 \%$, with a spatial distribution similar to that shown in Figure 8b. Regions of high latitude were dominated by one month of cumulative effects, while other regions experienced these effects between seven and nine months (the start of the growing season to the early summer of the previous year), and six months (early autumn to the end of the growing season of the following year). During those six months, which accounted for $23.22 \%$ of the total pixels, the $R_{a c c m a x}-g s$ for $\mathrm{SM}$ was positively correlated with $\mathrm{NDVI}_{\mathrm{gs}}$ up to $77.45 \%$, including $19.25 \%$ of pixels at a significance level of $95 \%$. The one-month-period was the period of time in which the highest percentage of cumulative effects $(25.54 \%)$ occurred, followed by three months (12.97\%); this was particularly the case for the typical and desert steppes. The $R_{a c c m a x}-g s$ of the three temperature variables exhibited relatively consistent spatial characteristics. For Tem, Tmax, and Tmin, the proportion of pixels that were positively 
correlated to $\mathrm{NDVI}_{\mathrm{gs}}$ was $77.45 \%, 70.40 \%$, and $75.12 \%$, respectively. Higher temperatures over one or two months promotes vegetation growth, which may be related to an earlier onset of greening-up for vegetation. This earlier onset results in a longer phenological period, particularly for vegetation in the high latitudes [55].

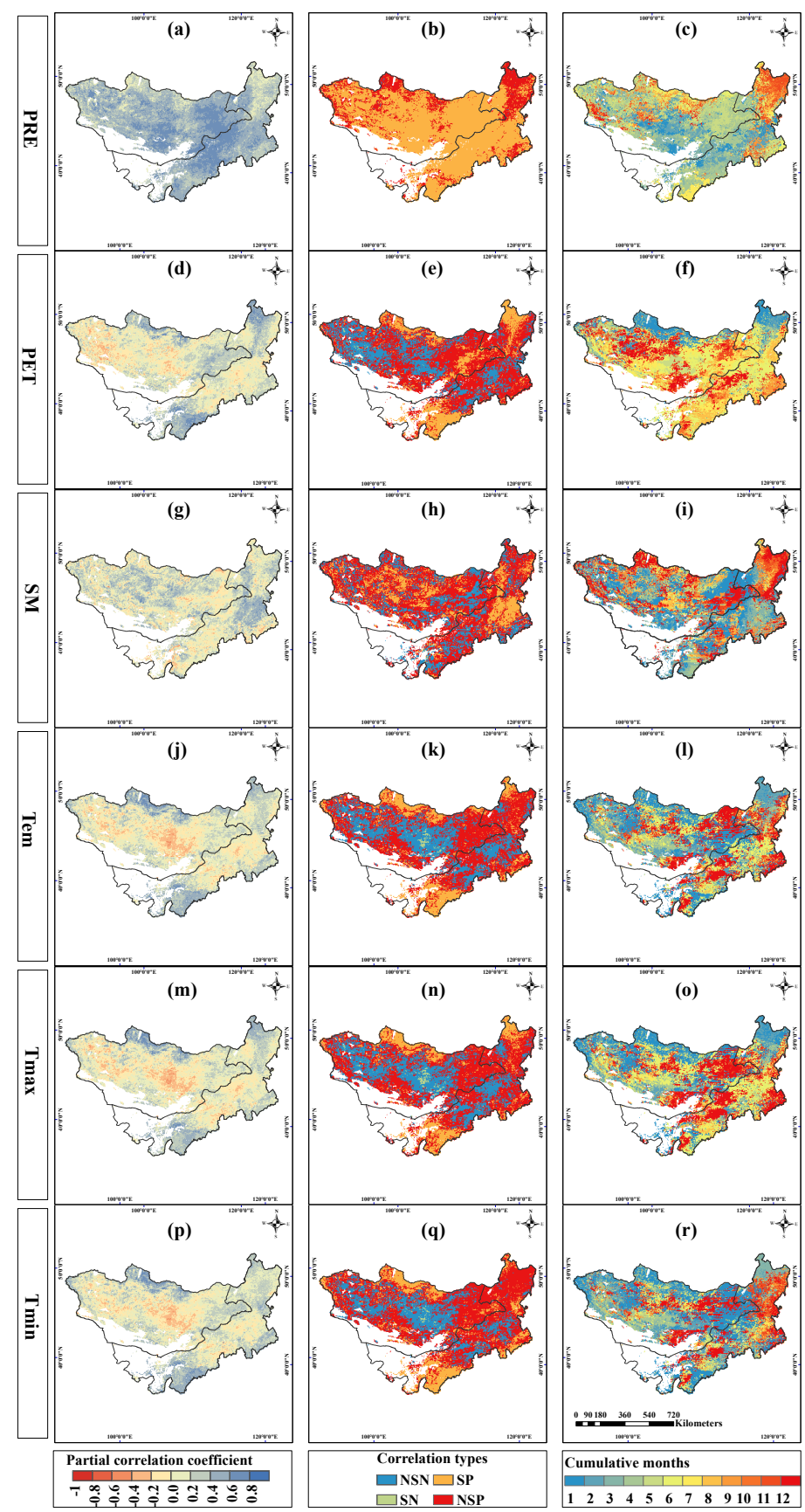

Figure 9. Spatial distribution of the cumulative effects of climatic factors on the NDVI gs $_{\text {for }}$ 19822015 in the Mongolian Plateau. The panels on the right-hand side represent spatial distribution of the maximum partial correlation coefficients (i.e., $R_{a c c m a x}-g s$ ). The panels in the centre represent the type of partial correlation coefficients. The panels on the left-hand side represent the spatial patterns of the corresponding time scales (i.e., accumulated months) where $R_{a c c m a x-g s}$ occurred. NSN: non-significant negative correlation; SN: significant negative correlation; SP: significant positive correlation; NSP: non-significant positive correlation. (a-c) PRE(precipitation), (d-f), PET(potential evapotranspiration), (g-i) SM(soil moisture), (j-1) Tem(mean temperature), (m-o) Tmax(maximum temperature), (p-r) Tmin(minimum temperature). 


\subsection{Vegetation Responses to Anthropogenic Factors}

Meteorological factors are important drivers of vegetation change, particularly in steppes, where the influence of climate on steppe vegetation is often magnified. However, with rapid urbanisation and industrialisation, anthropogenic activities have become one of the driving factors for climate change, becoming hugely influential on observed climate variations [56]. In this research, the RESTREND method was used to separate the effects of meteorological factors and anthropogenic activity on vegetation change, where ecosystem responsiveness to anthropogenic activity was measured by the residual $\varepsilon$. A positive $\varepsilon$ indicates that anthropogenic activity promotes vegetation growth, while a negative $\varepsilon$ is indicative of a negative effect on vegetation growth. The results show that the residual values showed a positive trend for $81.21 \%$ of the study area, in which $19.87 \%$ of the pixels showed a significant trend. This mainly occurred in the northeastern part of Mongolia and the bordering areas with China, although it was also sporadic in other areas, including the eastern Xing' an League, and the southern Chifeng and Hohhot, China. This demonstrates that anthropogenic influence dominates vegetation variations on the Mongolian Plateau (Figure 10). Areas with a negative trend of residual values showed strong consistency with the urban and rural distribution, indicating that the vegetation near settlements was more severely negatively disturbed by anthropogenic activity such as urban expansion and road construction during rapid economic development and population growth. The Chinese and Mongolian governments have implemented efforts towards increased environmental protection and ecological restoration [57]. These efforts have stabilised the land degradation that was occurring in the Mongolian Plateau. For example, over 19000 ha of degraded forest has been restored and successfully reforested between 1971 and 2011 [58]. In particular, Dornod, Khentii, and Sukhbaatar of Mongolia are a testament that anthropogenic activities substantially contribute to increasing NDVI. This may be related to the development of the Kherlen River basin and the restored management of mining areas [59,60]. Overall, anthropogenic activity was observed to have a strong impact on vegetation growth on the Mongolian Plateau.

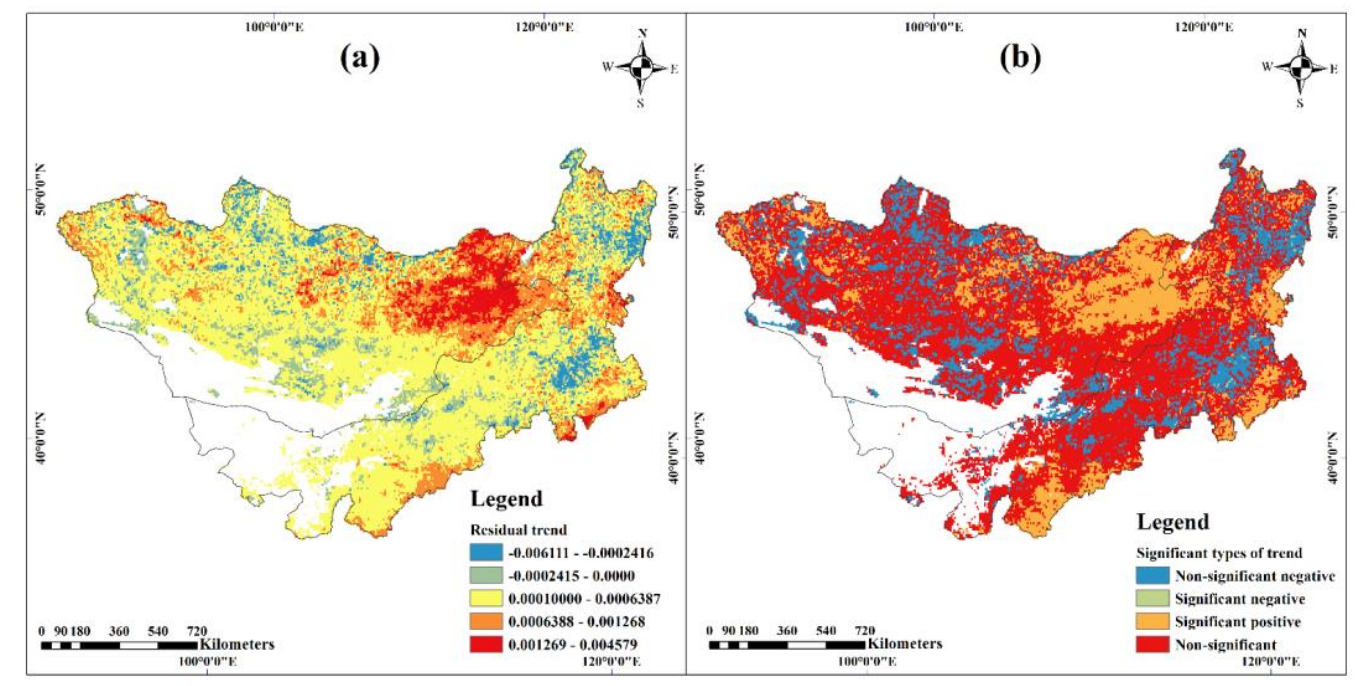

Figure 10. Spatial distribution of the effect of anthropogenic factors on mean growing season normalised difference vegetation index (NDVI) in the Mongolian Plateau using the RESTREND method. (a) the residual trend using linear regression method, (b) the residual trend at the 95\% confidence level.

\subsection{Vegetation Responses to the Combined Effects of Climate Change and Anthropogenic Factors}

It is difficult to disentangle the effects of climate change from those of anthropogenic factors on the NDVI, as they are strongly coupled through human-and interactions. To detect vegetation responses to climate change and anthropogenic factors, we compared their 
relative importance for the $\mathrm{NDVI}_{\mathrm{gs}}$ on the Mongolian Plateau with those at the national level (as shown in Figure 11). The results show that all climatic factors contributions to NDVI changes exceeded 50\% at the Mongolian Plateau, demonstrating that the Mongolian Plateau is mainly influenced by meteorological factors, which is consistent with previous results. The exception to this result was the cumulative contribution of meteoro-logical factors to changes in NDVI as quantified using the first method, which was $49.35 \%[20,61]$. In addition, the dominant anthropogenic factors influencing NDVI changes were mainly the economic activity and population growth. The contribution of GDP to NDVI obtained by the four methods was between $20.74 \%$ and $29.30 \%$. The dominant meteorological factors were mainly PRE and SM, in which the contribution of PRE to NDVI fell between 17.69\% and $30.60 \%$, and SM fell between $13.32 \%$ and $20.02 \%$. The other contributions were less than $10 \%$, indicating that PRE was the most important factor influencing vegetation growth. For Mongolia and the IMG Autonomous Region of China, the factors that governed vegetation change varied in terms of their level of influence due to differences in systems and economic structures; among all factors, the GDP, PRE, and SM were ranked in the top three. This indicates that rapid economic growth within the IMG is the main anthropogenic factor affecting vegetation variation. In Mongolia, the PRE (with a relative importance ranging from $22.12 \%$ to $31.19 \%$ ), was the main climatic factor affecting vegetation change, while population (with a contribution rate between $13.67 \%$ and $32.08 \%$ ) and livestock were the main anthropogenic factors.

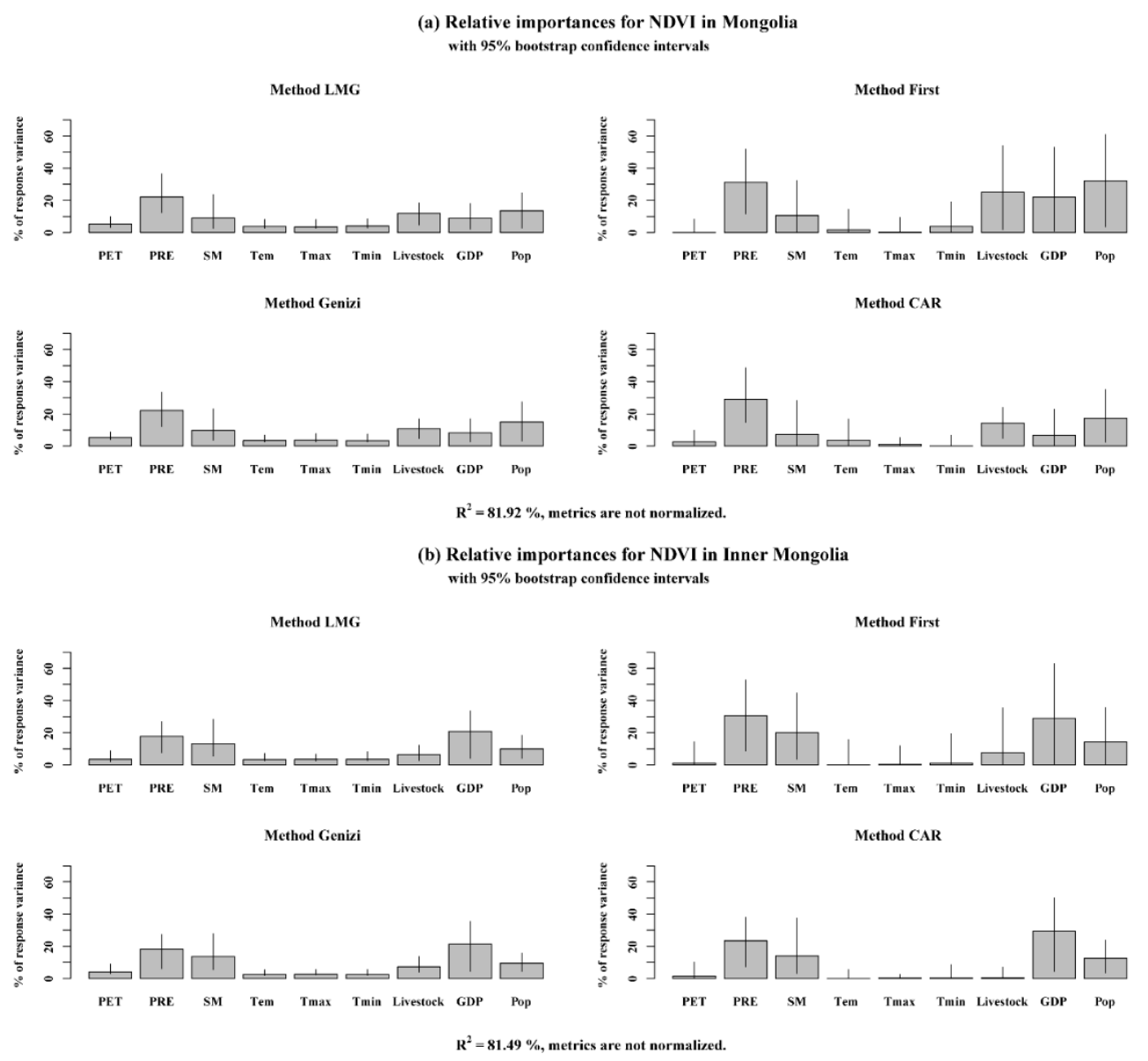

Figure 11. Cont. 


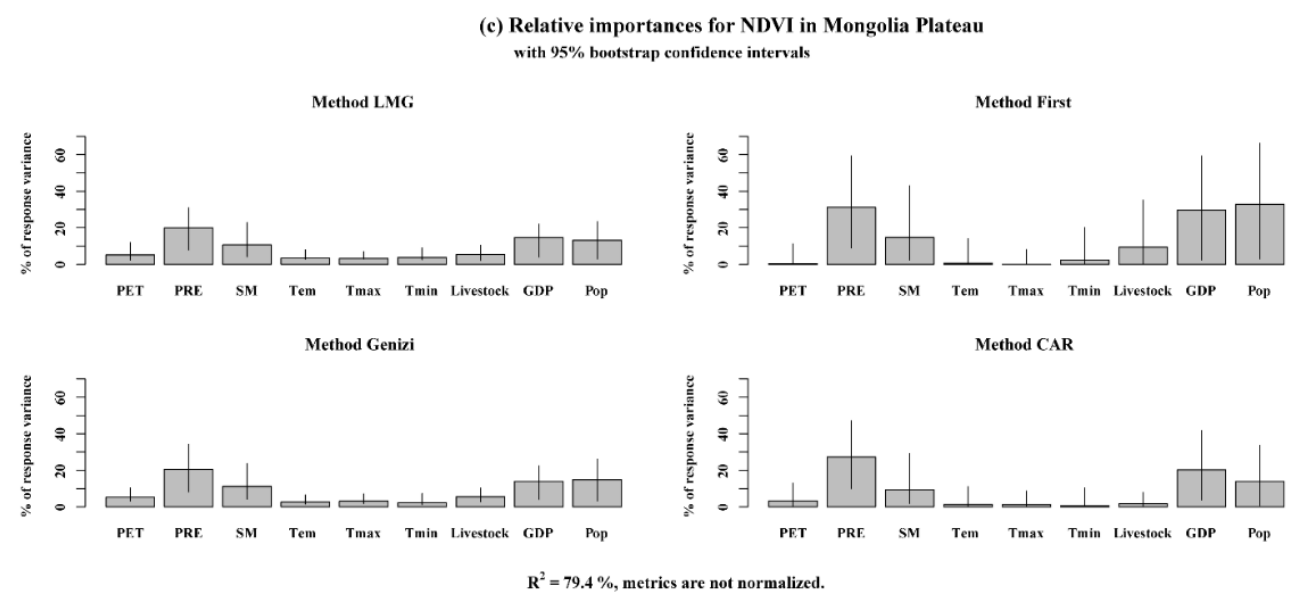

Figure 11. Relative importance of climatic and anthropogenic factors for the mean growing season NDVI in the Mongolia (a), Inner Mongolia (b), and whole Mongolian Plateau (c).

\section{Discussion}

The shifts and dynamics of the different vegetation types may also be induced by anthropogenic perturbations as well as being related to the BP of natural factors. These activities include grazing, afforestation, policy-driven land use conversions, ecological restoration, mining, and urban expansion. The turning point of vegetation change may be divided into several types, such as statistically insignificant and significant increases. The Chinese and Mongolian governments differ in terms of institutional and socioeconomic trajectories, and these differences have magnified over the past century. In the IMG, particularly in the central region, persistent overgrazing has exceeded the capacity of the available pastureland. As such, in the 1990s the local and central governments implemented a grazing exclusion policy including the Three-North Shelter Forest Program (TNSFP), the Grain to Green Program (GGP), and the Natural Forest Protection Program (NFPP). Fenced grassland patches were established to exclude grazing activity; these management actions may promote green ecosystem practices and conditions in the IMG $[62,63]$. In addition, increasing land degradation led to a series of legislative controls to minimise land degradation in Mongolia; these includes the Issue Mongolia Land Law, the Law of Land Privatisation for Mongolian citizens in 2002, and nationally appropriate mitigation action (NAMA) for steppe and livestock management in 2010 [64].The transfer matrix of land cover demonstrates that shrubland and tree cover were largely driven by bare areas, in which 19575.36 and $10607.49 \mathrm{~km}^{2}$ of land were transferred from bare areas for 1992-2015, respectively. Further analysis of this transfer matrix of land cover from 1993-2003, shows that $11094.12 \mathrm{~km}^{2}$ of land was transferred to bare areas. These results (Figure 12b), show that China and Mongolia have strengthened their efforts to control desertification in which during 2003-2010, 8304.93 and $6395.04 \mathrm{~km}^{2}$ of land has been transferred to shrubland and tree cover from bare areas, respectively (Figure 12c). Almost all livestock in Mongolia is now privately owned by rural residents since the collapse of the Soviet Union. Since 1993, herders have raised many farm animals to increase their income. Between 1999 and 2002, snow and drought disasters frequently occur in the Mongolian Plateau, and an unusual heavy snow disaster occurred in Mongolia in 2010, leading to a dramatic decline in the number of livestock within this period [65]. The results show that the change point of livestock is highly consistent with the change point of NDVI (Figure 12a). In terms of the population and GDP of Mongolia and the IMG, there is a significant growth trend (Figure 13b,c). Currently, the population of Mongolia is mainly migrating to Ulaanbaatar; as such there has been a dramatic increase in the urban population [66]. These institutional arrangements have improved vegetation restoration on the Mongolian Plateau. 


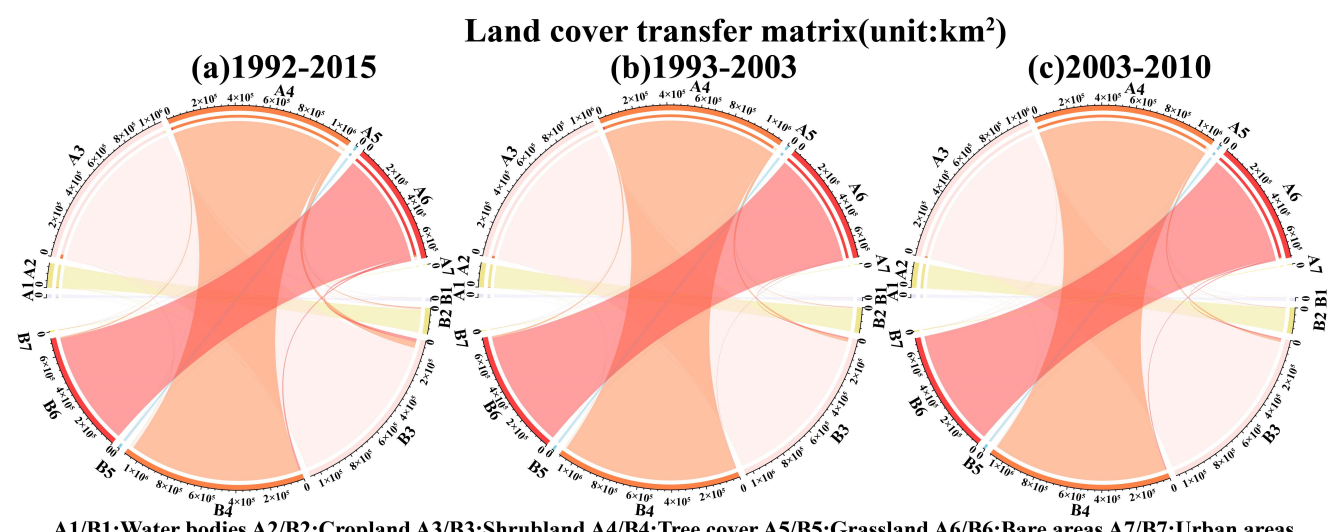

Figure 12. Transfer matrix of land cover for 1992-2015 in the Mongolian Plateau. (a) land cover transfer from 1992 to 2015, (b) land cover transfer area from 1992 to 2003, (c) land cover transfer area from 2003 to 2015 .
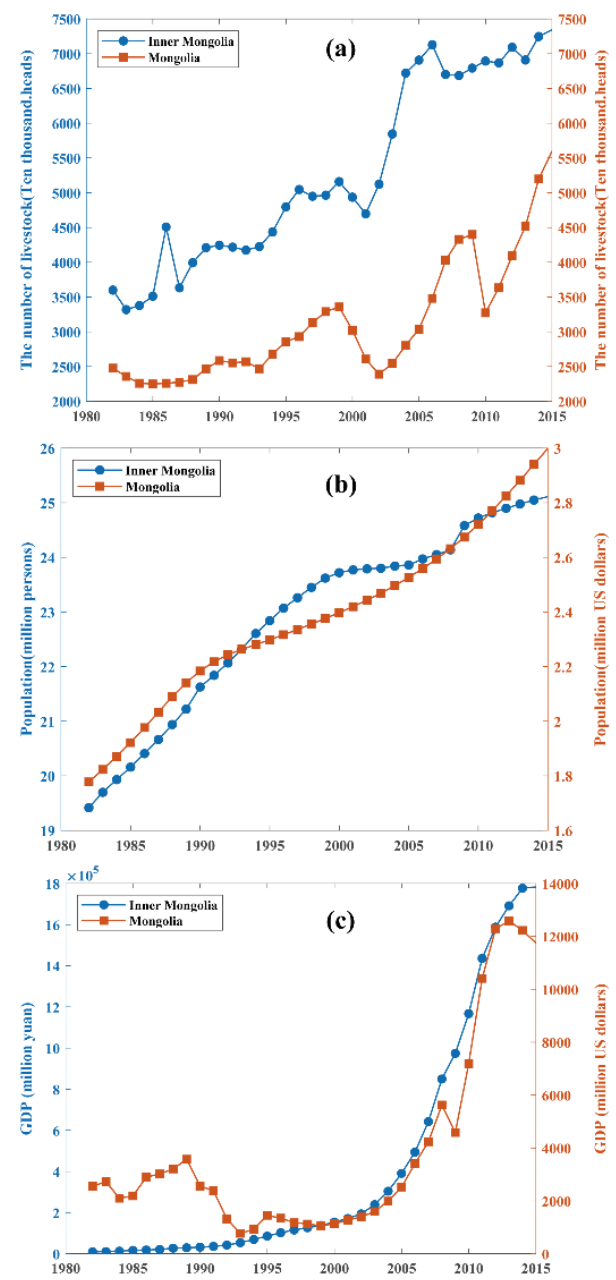

Figure 13. The linear trends in specific socioeconomic indicators for 1982-2015 in the Mongolian Plateau. (a) the numbers of livestock, (b) human population (Pop), (c) gross domestic product (GDP).

This study shows that vegetation has experienced a greening trend over the entire Mongolian Plateau, consistent with recent findings [67]. The literature on the Mongolian Plateau has reported on the contributions of climatic drivers to vegetation dynamics $[16,18,23,26]$. The rate of temperature increase on the Mongolia Plateau was faster than that of global 
warming, which may enhance vegetation activity and lengthen the growing season. This study observed a strong relationship between the NDVI and PRE in the agricultural vegetation and steppes of the Mongolian Plateau, while PRE had a lower impact than that of temperature in forests. This may be because agricultural vegetation and steppes are more sensitive to PRE than forests. The PET was found to generally reduce water availability and limit SM, particularly in high-latitude regions. We observed a prolonged PRE before the growing season and a short-medium term warming phenomena promoted vegetation growth, as did SM. The high latitude regions were dominated by longer periods in which the cumulative effects of PRE and SM were apparent. Moreover, the increased frequency and intensity of extreme weather events, such as droughts, are likely to cause major changes in vegetation cover. Unprecedented heatwave-drought concurrences over inner East Asia have been reported in the past two decades, impacting vegetation cover through changes such as increased tree mortality, particularly in Mongolia and Northern China [53].

It is important to emphasise that these are preliminary findings on vegetation responses and the driving climatic and anthropogenic factors, in which several relevant questions remain unanswered. The low spatial resolution $(8 \mathrm{~km})$ of the GIMMS NDVI3g data used in this research may eliminate phenological characteristics, or some normal ecological success of vegetation. In future, the use of the Google Earth platform may improve the certainty of further research as the Landsat and Sentinel datasets, open-source change detection algorithms and powerful computer servers are more easily accessible. Combining this theoretical analysis with ground observation data, may enable further analysis of the temporal variability of living biomass orLeaf Area Index (LAI) using NDVI as an intermediate characteristic. For example, estimating biomass using LAI or NDVI derived from Landsat 8 and Sentinel-2 data. This study used reanalysis data for the climatic factors and three indicators to characterise the impact of anthropogenic activity on vegetation. There are many other anthropogenic indicators that were not considered in the study, which may result in greater uncertainty in the accuracy of result while allowing for a more complete analysis. However, the analysis presented here is considered useful as it provides a flexible method to aggregate existing knowledge on long-term vegetation dynamics and the driving climatic and anthropogenic factors. Such a method will aid in the implementation of mitigation and planning measures to improve vegetation condition in the Mongolian Plateau.

\section{Conclusions}

After exploring the climatic and vegetation change characteristics, this study offers an improved understanding of the effect of climatic and anthropogenic factors on NDVI on the Mongolian Plateau for the 1982-2015 period. We attempted to differentiate between anthropogenic-induced and climate-driven vegetation dynamics. The detailed conclusions are as follows:

1. For the entire Mongolian Plateau, there was a statistically significant increase in the PRE and SM at a rate of -10.48 and $-1.19 \mathrm{~mm} /$ decade during the growing season, respectively. The mean temperature was observed to increase at a greater rate than that of worldwide global warming, resulting in a significant increase in PET at a rate of $2.99 \mathrm{~mm} /$ decade. The Tem of all pixels showed a significant increasing trend, while the PRE in $89.56 \%$ of the study area showed a decreasing trend.

2. There was significant spatial heterogeneity in changes to the NDVI for various vegetation types in the Mongolian Plateau. We found a fluctuation in the NDVI and an overall increasing trend from 1982-2015, with the except for broadleaf forests.

3. At the pixel scale, BFAST detected trend variations showed that the total number of one or more BPs accounted for $71.34 \%$ of pixels, and 1993, 2003, and 2010 were the predominant years in which abrupt NDVI changes occurred on the Mongolian Plateau.

4. All six climate factors (PRE, PET, SM, Tem, Tmax, and Tmin) had a significant influence on interannual $\mathrm{NDVI}_{\mathrm{gs}}$ variations, with large spatio-temporal heterogeneities. The interaction between climatic factors followed a bi-variable enhancement pattern. 
Moreover, PRE was the main climatic factor that positively influenced change in $\mathrm{NDVI}_{\mathrm{gs}}$, accounting for $75.01 \%$ of the region, while the dominant mean NDVI $\mathrm{Is}_{\mathrm{s}}$ change pattern was negatively correlated with PET, accounting for $55.97 \%$ of the area. The cumulative effects of climatic factors varied in terms of their influence on vegetation change.

5. The results of the RESTREND method showed that $81.21 \%$ of the vegetation was positively influenced by anthropogenic activity on the Mongolian Plateau. However, there were multiple driving factors for vegetation changes in different regions. Specifically, the rapid economic growth (GDP), PRE, and SM were the key factors in IMG, while in Mongolia, PRE was the main climatic factor, while population and livestock were the key anthropogenic factors.

Supplementary Materials: The following are available online at https:/ / www.mdpi.com/2072-429 2/13/4/688/s1, Figure S1: Spatial distribution of multi-year average climate factors during growing season of 1982-2015 in Mongolia Plateau. (a) PRE, (b) PET, (c) SM, (d) Tem, (e) Tmax, (f) Tmin. Figure S2: Spatial distribution of multi-year average (a), change trend (b) and the significant levels (c) of NDVI during growing season from 1982 to 2015 in Mongolia Plateau.

Author Contributions: E.G., conceptualization, methodology, writing-original draft; Y.W., conceptualization, supervision; C.W., writing-review and editing; Z.S., software; Y.B. (Yulong Bao), visualization; N.M., investigation; B.J., investigation; Y.B. (Yuhai Bao), investigation; H.L., validation. All authors have read and agreed to the published version of the manuscript.

Funding: The project was supported by the Natural Science Foundation of Inner Mongolia Autonomous Region of China (2020LH04003), the National Natural Science Foundation of China (41807507 and 41801353), the Drought Meteorology Science Research Program (IAM201904). Highlevel introduction of talent research start-up fund in Inner Mongolia Normal University (2018YJRC008 and 2019YJRC003). The Key Program of National Natural Science Foundation of China (61631011). Science and technology planning project in Inner Mongolia (201702116).

Institutional Review Board Statement: Not applicable.

Informed Consent Statement: Not applicable.

Data Availability Statement: Not applicable.

Acknowledgments: The authors would like to thank the Editors and the anonymous reviewers for their crucial comments, which improved the quality of this paper.

Conflicts of Interest: The authors declare no conflict of interest.

\section{References}

1. Piedallu, C.; Cheret, V.; Denux, J.P.; Perez, V.; Azcona, J.S.; Seynave, I.; Gegout, J.C. Soil and climate differently impact NDVI patterns according to the season and the stand type. Sci. Total Environ. 2019, 651, 2874-2885. [CrossRef]

2. Cao, R.; Chen, Y.; Shen, M.; Chen, J.; Zhou, J.; Wang, C.; Yang, W. A simple method to improve the quality of NDVI time-series data by integrating spatiotemporal information with the Savitzky-Golay filter. Remote Sens. Environ. 2018, 217, 244-257. [CrossRef]

3. Fang, H.; Baret, F.; Plummer, S.; Schaepman Strub, G. An Overview of Global Leaf Area Index (LAI): Methods, Products, Validation, and Applications. Rev. Geophys. 2019, 57, 739-799. [CrossRef]

4. Zhang, Z.; Zhang, Y.; Zhang, Y.; Gobron, N.; Frankenberg, C.; Wang, S.; Li, Z. The potential of satellite FPAR product for GPP estimation: An indirect evaluation using solar-induced chlorophyll fluorescence. Remote Sens. Environ. 2020, $240,111686$. [CrossRef]

5. Zewdie, W.; Csaplovics, E.; Inostroza, L. Monitoring ecosystem dynamics in northwestern Ethiopia using NDVI and climate variables to assess long term trends in dryland vegetation variability. Appl. Geogr. 2017, 79, 167-178. [CrossRef]

6. Ye, W.T.; van Dijk, A.I.J.M.; Huete, A.; Yebra, M. Global trends in vegetation seasonality in the GIMMS NDVI3g and their robustness. Int. J. Appl. Earth Obs. Geoinf. 2021, 94, 102238. [CrossRef]

7. Sun, R.; Chen, S.H.; Su, H.B. Climate Dynamics of the Spatiotemporal Changes of Vegetation NDVI in Northern China from 1982 to 2015. Remote Sens. 2021, 13, 187. [CrossRef]

8. Li, J.; Fan, K.; Xu, J.; Powell, A.M.; Kogan, F. The effect of preceding wintertime Arctic polar vortex on springtime NDVI patterns in boreal Eurasia, 1982-2015. Clim. Dyn. 2017, 49, 23-35. [CrossRef]

9. Chen, T.; de Jeu, R.A.M.; Liu, Y.Y.; van der Werf, G.R.; Dolman, A.J. Using satellite based soil moisture to quantify the water driven variability in NDVI: A case study over mainland Australia. Remote Sens. Environ. 2014, 140, 330-338. [CrossRef] 
10. Jamali, S.; Seaquist, J.; Eklundh, L.; Ardö, J. Automated mapping of vegetation trends with polynomials using NDVI imagery over the Sahel. Remote Sens. Environ. 2014, 141, 79-89. [CrossRef]

11. Xu, X.; Liu, H.; Lin, Z.; Jiao, F.; Gong, H. Relationship of Abrupt Vegetation Change to Climate Change and Ecological Engineering with Multi-Timescale Analysis in the Karst Region, Southwest China. Remote Sens. 2019, 11, 1564. [CrossRef]

12. Militino, A.F.; Moradi, M.; Ugarte, M.D. On the Performances of Trend and Change-Point Detection Methods for Remote Sensing Data. Remote Sens. 2020, 12, 1008. [CrossRef]

13. Zhang, P.P.; Cai, Y.P.; Yang, W.; Yi, Y.Y.; Yang, Z.F.; Fu, Q. Contributions of climatic and anthropogenic drivers to vegetation dynamics indicated by NDVI in a large dam-reservoir-river system. J. Cleaner Prod. 2020, 256, 120477. [CrossRef]

14. Wen, Z.F.; Wu, S.J.; Chen, J.L.; Lü, M.Q. NDVI indicated long-term interannual changes in vegetation activities and their responses to climatic and anthropogenic factors in the Three Gorges Reservoir Region, China. Sci. Total Environ. 2017, 574, 947-959. [CrossRef]

15. Han, D.; Gao, C.; Liu, H.; Yu, X.; Li, Y.; Cong, J.; Wang, G. Vegetation dynamics and its response to climate change during the past 2000 years along the Amur River Basin, Northeast China. Ecol. Indic. 2020, 117, 106577. [CrossRef]

16. Kern, A.; Marjanović, H.; Barcza, Z. Spring vegetation green-up dynamics in Central Europe based on 20-year long MODIS NDVI data. Agr. Forest Meteorol. 2020, 287, 107969. [CrossRef]

17. Linscheid, N.; Estupinan-Suarez, L.M.; Brenning, A.; Carvalhais, N.; Cremer, F.; Gans, F.; Rammig, A.; Reichstein, M.; Sierra, C.A.; Mahecha, M.D. Towards a global understanding of vegetation-climate dynamics at multiple timescales. Biogeosciences 2020, 17, 945-962. [CrossRef]

18. Peng, W.; Kuang, T.; Tao, S. Quantifying influences of natural factors on vegetation NDVI changes based on geographical detector in Sichuan, western China. J. Clean. Prod. 2019, 233, 353-367. [CrossRef]

19. Zhou, X.; Yamaguchi, Y.; Arjasakusuma, S. Distinguishing the vegetation dynamics induced by anthropogenic factors using vegetation optical depth and AVHRR NDVI: A cross-border study on the Mongolian Plateau. Sci. Total Environ. 2018, 616, 730-743. [CrossRef]

20. Gang, C.; Wei, Z.; Chen, Y.; Wang, Z.; Sun, Z.; Li, J.; Qi, J.; Odeh, I. Quantitative assessment of the contributions of climate change and human activities on global grassland degradation. Environ. Earth Sci. 2014, 72, 4273-4282. [CrossRef]

21. Zhang, Y.; Wang, Q.; Wang, Z.; Yang, Y.; Li, J. Impact of human activities and climate change on the grassland dynamics under different regime policies in the Mongolian Plateau. Sci. Total Environ. 2020, 698, 134304. [CrossRef]

22. Fan, D.; Ni, L.; Jiang, X.; Fang, S.; Wu, H.; Zhang, X. Spatiotemporal Analysis of Vegetation Changes along the Belt and Road Initiative Region from 1982 to 2015. IEEE Access 2020, 8, 122579-122588. [CrossRef]

23. Ying, H.; Zhang, H.; Zhao, J.; Shan, Y.; Zhang, Z.; Guo, X.; Rihan, W.; Deng, G. Effects of spring and summer extreme climate events on the autumn phenology of different vegetation types of Inner Mongolia, China, from 1982 to 2015. Ecolo. Indic. 2020, 111, 105974. [CrossRef]

24. Bao, G.; Chen, J.; Chopping, M.; Bao, Y.; Bayarsaikhan, S.; Dorjsuren, A.; Tuya, A.; Jirigala, B.; Qin, Z. Dynamics of net primary productivity on the Mongolian Plateau: Joint regulations of phenology and drought. Int. J. Appl. Earth Obs. 2019, 81, 85-97. [CrossRef]

25. Jin, H.; Bao, G.; Chen, J.; Chopping, M.; Jin, E.; Mandakh, U.; Jiang, K.; Huang, X.; Bao, Y.; Vandansambuu, B. Modifying the maximal light-use efficiency for enhancing predictions of vegetation net primary productivity on the Mongolian Plateau. Int. J. Remote Sens. 2019, 41, 3740-3760. [CrossRef]

26. Bao, G.; Bao, Y.; Sanjjava, A.; Qin, Z.; Zhou, Y.; Xu, G. NDVI-indicated long-term vegetation dynamics in Mongolia and their response to climate change at biome scale. Int. J. Climatol. 2015, 35, 4293-4306. [CrossRef]

27. Rogers, A.; Medlyn, B.E.; Dukes, J.S. A roadmap for improving the representation of photosynthesis in Earth system models. New Phytol. 2017, 213, 22-42. [CrossRef] [PubMed]

28. Kottek, M.; Grieser, J.; Beck, C.; Rudolf, B.; Rubel, F. World map of the Köppen-Geiger climate classification updated. Meteorol. Z. 2006, 15, 259-263. [CrossRef]

29. Dong, G.; Zhao, F.Y.; Chen, J.Y.; Zhang, Y.; Qu, L.P.; Jiang, S.C.; Ochirbat, B.; Chen, J.Y.; Xin, X.P.; Shao, C.L. Non-climatic component provoked substantial spatiotemporal changes of carbon and water use efficiency on the Mongolian Plateau. Environ. Res. Lett. 2020, 15, 095009. [CrossRef]

30. Tong, S.; Zhang, J.; Ha, S.; Lai, Q.; Ma, Q. Dynamics of Fractional Vegetation Coverage and Its Relationship with Climate and Human Activities in Inner Mongolia, China. Remote Sens. 2016, 8, 776. [CrossRef]

31. Bao, G.; Bao, Y.; Qin, Z.; Xin, X.; Bao, Y.; Bayarsaikan, S.; Zhou, Y.; Chuntai, B. Modeling net primary productivity of terrestrial ecosystems in the semi-arid climate of the Mongolian Plateau using LSWI-based CASA ecosystem model. Int. J. Appl. Earth Obs. 2016, 46, 84-93. [CrossRef]

32. Pinzon, J.E. A Non-Stationary 1981-2015 AVHRR NDVI 3g Time Series. In Proceedings of the AGU Fall Meeting, San Francisco, CA, USA, 14-18 December 2015.

33. Abatzoglou, J.T.; Dobrowski, S.Z.; Parks, S.A.; Hegewisch, K.C. TerraClimate, a high-resolution global dataset of monthly climate and climatic water balance from 1958-2015. Sci. Data 2018, 5, 170191. [CrossRef] [PubMed]

34. Liu, Z.; Wu, C.; Liu, Y.; Wang, X.; Fang, B.; Yuan, W.; Ge, Q. Spring green-up date derived from GIMMS3g and SPOT-VGT NDVI of winter wheat cropland in the North China Plain. ISPRS J. Photogramm. 2017, 130, 81-91. [CrossRef] 
35. Verbesselt, J.; Hyndman, R.; Newnham, G.; Culvenor, D. Detecting trend and seasonal changes in satellite image time series. Remote Sens. Environ. 2010, 114, 106-115. [CrossRef]

36. Wang, Y.; Liu, G.; Guo, E. Spatial distribution and temporal variation of drought in Inner Mongolia during 1901-2014 using Standardized Precipitation Evapotranspiration Index. Sci. Total Environ. 2019, 654, 850-862. [CrossRef]

37. Song, Y.Z.; Wang, J.F.; Ge, Y.; Xu, C.D. An optimal parameters-based geographical detector model enhances geographic characteristics of explanatory variables for spatial heterogeneity analysis: Cases with different types of spatial data. Gisci. Remote Sens. 2020, 57, 593-610. [CrossRef]

38. Wang, J.F.; Li, X.H.; Christakos, G.; Liao, Y.L.; Zhang, T.; Gu, X.; Zheng, X.Y. Geographical Detectors-Based Health Risk Assessment and its Application in the Neural Tube Defects Study of the Heshun Region, China. Int. J. Geogr. Inf. Sci 2010, $24,107-127$. [CrossRef]

39. Evans, J.; Geerken, R. Discrimination between climate and human-induced dryland degradation. J. Arid Environ. 2014, 57, 535-554. [CrossRef]

40. Chu, H.; Venevsky, S.; Wu, C.; Wang, M. NDVI-based vegetation dynamics and its response to climate changes at AmurHeilongjiang River Basin from 1982 to 2015. Sci. Total Environ. 2019, 650, 2051-2062. [CrossRef] [PubMed]

41. Groemping, U. Relative Importance for linear regression in R: The package relaimpo. J. Statal. Softw. 2016, 17, 925-933.

42. Yin, L.; Feng, X.; Fu, B.; Chen, Y.; Wang, X.; Tao, F. Irrigation water consumption of irrigated cropland and its dominant factor in China from 1982 to 2015. Adv. Water Resour. 2020, 143, 103661. [CrossRef]

43. NOAA. State of the Climate: Global Climate Report for January 2019, Published Online February 2019. Available online: https:/ / www.ncdc.noaa.gov/sotc/global/201901 (accessed on 26 September 2020).

44. Allington, G.R.H.; Li, W.; Brown, D.G. Urbanization and environmental policy effects on the future availability of grazing resources on the Mongolian Plateau: Modeling socio-environmental system dynamics. Environ. Sci. Policy 2017, 68, 35-46. [CrossRef]

45. Rihan, W.; Zhao, J.; Zhang, H.; Guo, X.; Ying, H.; Deng, G.; Li, H. Wildfires on the Mongolian Plateau: Identifying Drivers and Spatial Distributions to Predict Wildfire Probability. Remote Sens. 2019, 11, 2361. [CrossRef]

46. Qiu, B.; Chen, G.; Tang, Z.; Lu, D.; Wang, Z.; Chen, C. Assessing the Three-North Shelter Forest Program in China by a novel framework for characterizing vegetation changes. ISPRS J. Photogramm. 2017, 133, 75-88. [CrossRef]

47. Guo, L.; Wu, S.; Zhao, D.; Yin, Y.; Leng, G.; Zhang, Q. NDVI-based vegetation change in Inner Mongolia from 1982 to 2006 and its relationship to climate at the biome scale. Adv. Meteorol. 2014, 2014, 1-12. [CrossRef]

48. Fang, J.; Piao, S.; Zhou, L.; He, J.; Wei, F.; Myneni, R.B.; Tucker, C.J.; Tan, K. Precipitation patterns alter growth of temperate vegetation. Geophys. Res. Lett. 2005, 32, L21411. [CrossRef]

49. Piao, S.; Mohammat, A.; Fang, J.; Cai, Q.; Feng, J. NDVI-based increase in growth of temperate grasslands and its responses to climate changes in China. Global Environ. Chang. 2006, 16, 340-348. [CrossRef]

50. Asam, S.; Callegari, M.; Matiu, M.; Fiore, G.; De Gregorio, L.; Jacob, A.; Menzel, A.; Zebisch, M.; Notarnicola, C. Relationship between Spatiotemporal Variations of Climate, Snow Cover and Plant Phenology over the Alps-An Earth Observation-Based Analysis. Remote Sens. 2018, 10, 1757. [CrossRef]

51. Liu, L.; Gudmundsson, L.; Hauser, M.; Qin, D.; Li, S.; Seneviratne, S.I. Soil moisture dominates dryness stress on ecosystem production globally. Nat. Commun. 2020, 11,1-9.

52. Camps, A.; Park, H.; Pablos, M.; Foti, G.; Gommenginger, C.P.; Liu, P.W.; Judge, J. Sensitivity of GNSS-R spaceborne observations to soil moisture and vegetation. IEEE J-STARS 2016, 9, 4730-4742. [CrossRef]

53. Bradford, J.B.; Schlaepfer, D.R.; Lauenroth, W.K.; Palmquist, K.A. Robust ecological drought projections for drylands in the 21st century. Glob. Chang. Biol. 2020, 26, 3906-3919. [CrossRef]

54. Zhang, P.; Jeong, J.h.; Yoon, J.H.; Kim, H.; Wang, S.Y.; Linderholm, H.W.; Fang, K.Y.; Wu, X.C.; Chen, D.L. Abrupt shift to hotter and drier climate over inner East Asia beyond the tipping point. Science 2020, 370, 1095-1099. [CrossRef] [PubMed]

55. Piao, S.; Cui, M.; Chen, A.; Wang, X.; Ciais, P.; Liu, J.; Tang, Y. Altitude and temperature dependence of change in the spring vegetation green-up date from 1982 to 2006 in the Qinghai-Xizang Plateau. Agr. For. Meteorol. 2011, 151, 1599-1608. [CrossRef]

56. Yu, Z.; Li, Z.; Rasmus, F.; Kun, W.; Irina, V.; Feng, T. Climate contributions to vegetation variations in central Asian drylands: Preand Post-Ussr collapse. Remote Sens. 2015, 7, 2449-2470.

57. Zhou, Z.; Ding, Y.; Shi, H.; Cai, H.; Li, T. Analysis and prediction of vegetation dynamic changes in china: Past, present and future. Ecolo. Indic. 2012, 117, 106642. [CrossRef]

58. Gradel, A.; Sukhbaatar, G.; Karthe, D.; Kang, H. Forest management in Mongolia-A review of challenges and lessons learned with special reference to degradation and deforestation. Geogr. Environ. Sustain. 2019, 12, 133-166. [CrossRef]

59. Simonov, E.; Wickel, B. Kherlen River the Lifeline of the Eastern Steppe. Towards Integrated River Basin Management of the Dauria Steppe Transboundary River Basins by Rivers without Boundaries. 2016. Available online: http:/ /www.transrivers.org/ pdf/20150503Kherlen\%20RiverReport.Pdf (accessed on 1 December 2020).

60. Wei, Y.; Zhen, L. The dynamics of livestock and its influencing factors on the Mongolian Plateau. Environ. Dev. 2020, 34, 100518. [CrossRef]

61. Tong, S.; Zhang, J.; Bao, Y.; Lai, Q.; Lian, X.; Li, N.; Bao, Y. Analyzing vegetation dynamic trend on the Mongolian Plateau based on the hurst exponent and influencing factors from 1982-2013. J. Geogr. Sci. 2018, 28, 595-610. [CrossRef] 
62. Gao, L.; Kinnucan, H.W.; Zhang, Y.; Qiao, G. The effects of a subsidy for grassland protection on livestock numbers, grazing intensity, and herders' income in inner Mongolia. Land Use Policy 2016, 54, 302-312. [CrossRef]

63. Yang, H. China's Natural Forest Protection Program: Progress and impacts. For. Chron. 2017, 93, 113-117. [CrossRef]

64. Lee, D.; Ahn, G. A way forward to sustainable international forestry cooperation: A case study of the 'greenbelt plantation project in Mongolia'. J. Rural Dev. Nongchon-Gyeongje 2016, 39, 1-26.

65. Nandintsetseg, B.; Shinoda, M.; Erdenetsetseg, B. Contributions of multiple climate hazards and overgrazing to the $2009 / 2010$ winter disaster in Mongolia. Nat. Hazards 2018, 92, 109-126. [CrossRef]

66. Park, H.; Fan, P.; John, R.; Ouyang, Z.; Chen, J. Spatiotemporal changes of informal settlements: Ger districts in Ulaanbaatar, Mongolia. Landsc. Urban Plan. 2019, 191, 103630. [CrossRef]

67. Zhao, X.; Hu, H.; Shen, H.; Zhou, D.; Fang, J. Satellite-indicated long-term vegetation changes and their drivers on the Mongolian Plateau. Landsc. Ecol. 2015, 30, 1599-1611. [CrossRef] 